Check for updates

Cite this: RSC Adv., 2018, 8, 16069

Received 27th February 2018 Accepted 19th April 2018

DOI: $10.1039 / c 8 \mathrm{ra01744a}$

rsc.li/rsc-advances

\section{Predicting sulfur solubility in hydrogen sulfide, carbon dioxide, and methane with an improved thermodynamic model}

\begin{abstract}
Changjun Li, ${ }^{a}$ Gang Liu (iD *a and Yang Peng ${ }^{b}$
During development of high sulfur-content natural gas fields, gaseous sulfur is likely to precipitate and deposit in the reservoir and transmission pipelines owing to changes in the temperature, pressure, and gas components. It is important to accurately predict the elemental sulfur solubility in hydrogen sulfide, carbon dioxide, and methane because these are the three main components of high-sulfur-content natural gas. The binary interaction coefficients between sulfur and hydrogen sulfide, carbon dioxide, and methane are the key parameters for predicting the sulfur solubility with a thermodynamic model. In this work, we show that the binary interaction coefficients are not constant, but temperature dependent. Three-parameter temperature-dependent equations for the binary interaction coefficients between sulfur and solvents are proposed. The corresponding regression equations for calculating the binary interaction coefficients between sulfur and hydrogen sulfide, carbon dioxide, and methane are obtained using experimental sulfur solubility data. The average relative errors of the sulfur solubility predicted using the experimental data in hydrogen sulfide, carbon dioxide, and methane using the thermodynamic model with the improved binary interaction coefficients are $6.30 \%, 1.69 \%$, and $4.34 \%$, and the average absolute relative errors are $7.90 \%, 13.12 \%$, and $14.98 \%$, respectively. Comparing the improved binary interaction coefficients with four other sets of reported values shows that the solubility values predicted by the thermodynamic model with improved binary interaction coefficients fit the experimental data better.
\end{abstract}

\section{Introduction}

High-sulfur-content natural gas contains hydrogen sulfide, mercaptans, sulfoethers, and other sulfurous substances, with hydrogen sulfide gas comprising the majority of all sulfurous substances. There are many high-sulfur-content gas fields. For example, the hydrogen sulfide volume contents in natural gas mixtures are $15 \%$ to $18 \%$ in the Puguang Gas Field (China). ${ }^{1}$ High-sulfur-content natural gas fields supply not only clean energy, but also raw materials for sulfur series products. ${ }^{2}$ However, deposited elemental sulfur may cause pore formation, wellbore blockage, and even transmission pipeline blockage and corrosion with changes in pressure, temperature, and gas components. $^{3-5}$ This can lead to the normal production of the gas field being severely inhibited. ${ }^{6-9}$ In recent years, the problem of sulfur deposition has received extensive attention. Notably, elemental sulfur solubility in high-sulfur-content natural gas is the key factor determining whether sulfur deposition occurs. ${ }^{10-12}$

${ }^{a}$ School of Petroleum Engineering, Southwest Petroleum University, Chengdu 610500, China. E-mail: sci-tech@hotmail.com; Tel: +86132 28170900

${ }^{b}$ Gas Management Office, PetroChina Southwest Oil \& Gas Field Company, Chengdu 610215, China
Many researchers have measured the sulfur solubility in hydrogen sulfide $\left(\mathrm{H}_{2} \mathrm{~S}\right)$, carbon dioxide $\left(\mathrm{CO}_{2}\right)$, and methane $\left(\mathrm{CH}_{4}\right)$, because high- $\mathrm{H}_{2} \mathrm{~S}$-content natural gas mainly comprises these three gas components. Kennedy and Wieland ${ }^{3}$ were the first to measure elemental sulfur solubility in pure $\mathrm{H}_{2} \mathrm{~S}, \mathrm{CO}_{2}, \mathrm{CH}_{4}$ and their mixtures in 1960. Their work showed that elemental sulfur solubility increases with increasing pressure and temperature. Roof found that the solubility in $\mathrm{H}_{2} \mathrm{~S}$ first increases and then decreases with increasing temperature. ${ }^{13}$ Swift, Brunner, and Gu et al. extended the pressure and temperature range for sulfur solubility in $\mathrm{H}_{2} \mathrm{~S}^{.14-16}$ Serin et al. developed an experimental apparatus for measuring elemental sulfur solubility in $\mathrm{CO}_{2}{ }^{{ }^{17}}$ Using the same experimental apparatus, Cloarec et al. ${ }^{18}$ obtained experimental data of sulfur solubility in $\mathrm{CH}_{4}$.

The above experimental results of solubility in $\mathrm{H}_{2} \mathrm{~S}, \mathrm{CO}_{2}$, and $\mathrm{CH}_{4}$ provide the basis for establishing a solubility predicting model, and strongly support the development of high-sulfurcontent natural gas fields. ${ }^{19-24}$ The binary interaction coefficients between sulfur and $\mathrm{H}_{2} \mathrm{~S}, \mathrm{CO}_{2}$, and $\mathrm{CH}_{4}$ in natural gas are important parameters when using a thermodynamic predicting model based on the equation of state (EoS). As shown in Table 1, Heidemann ${ }^{25}$ reported that the binary interaction coefficients between sulfur and $\mathrm{H}_{2} \mathrm{~S}, \mathrm{CO}_{2}$, or $\mathrm{CH}_{4}$ after regression of the experimental data were $0.0812,0.135$, and 0.155 , respectively. ${ }^{25}$ In Sun's model, ${ }^{26}$ the binary interaction coefficients between 
Table 1 The binary interaction coefficient values

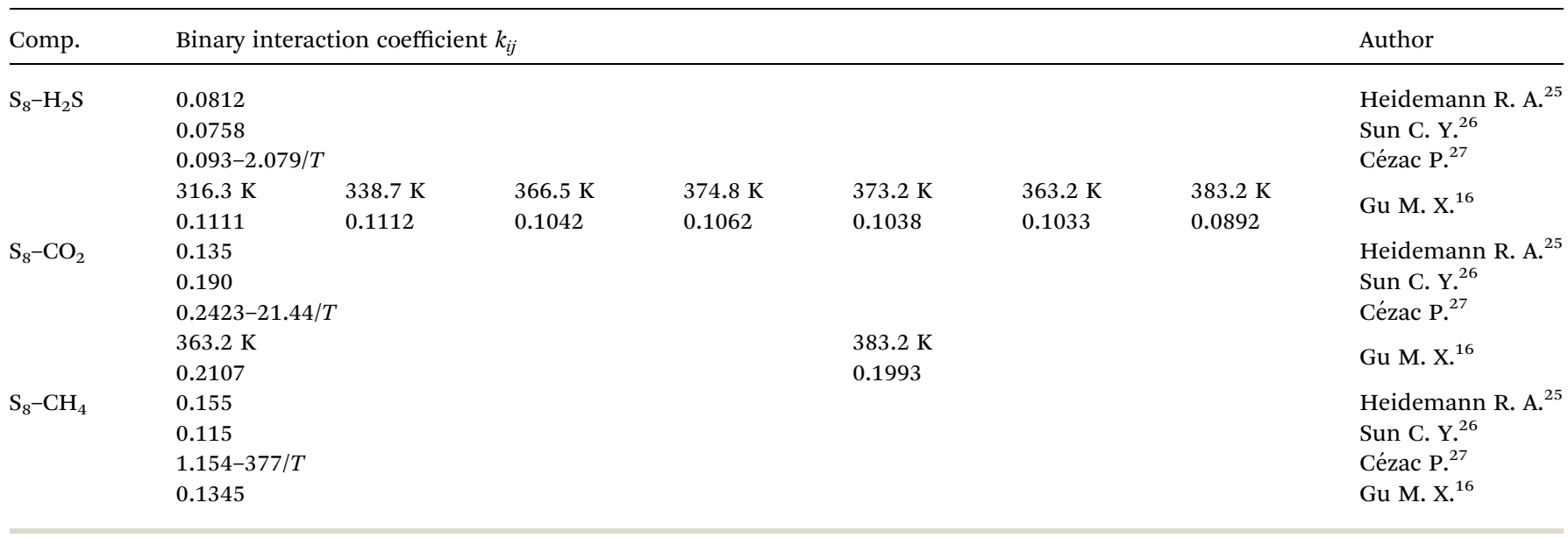

sulfur and $\mathrm{H}_{2} \mathrm{~S}, \mathrm{CO}_{2}$, and $\mathrm{CH}_{4}$ are $0.0758,0.190$, and 0.115, respectively. However, $\mathrm{Gu}^{16}$ and Cézac et al. ${ }^{27}$ suggested that the binary interaction coefficients are related to the gas mixture temperature. Based on the experimental data of Roof, Brunner, and their own work, $\mathrm{Gu}^{16}$ reported binary interaction coefficients between sulfur and $\mathrm{H}_{2} \mathrm{~S}, \mathrm{CO}_{2}$, and $\mathrm{CH}_{4}$ of $316.3-374.8 \mathrm{~K}$, 363.2 and $383.2 \mathrm{~K}$, and $383.2 \mathrm{~K}$, respectively. Cézac et al. ${ }^{27}$ proposed three equations for calculating the binary interaction coefficients between sulfur and $\mathrm{H}_{2} \mathrm{~S}, \mathrm{CO}_{2}$, and $\mathrm{CH}_{4}$ based on analysis of experimental data. The binary interaction coefficients from the above studies are considerably different, and it is unclear which set represents better experimental data.

This work aims to evaluate differences in the binary interaction coefficients between sulfur and $\mathrm{H}_{2} \mathrm{~S}, \mathrm{CO}_{2}$, and $\mathrm{CH}_{4}$. We investigated the relationships between the binary interaction coefficients and temperature to extend the range and improve the accuracy of predicting the sulfur solubility in $\mathrm{H}_{2} \mathrm{~S}, \mathrm{CO}_{2}$, and $\mathrm{CH}_{4}$ using a thermodynamic model based on the Peng-Robinson (PR) EoS. Based on experimental data analysis, new threeparameter temperature-dependent equations for calculating the binary interaction coefficients are proposed. The equation parameters are obtained by regression analysis of the experimental data. Furthermore, we compared the solubility results calculated using the thermodynamic model with the binary interaction coefficients reported by Heidemann, Sun, Cézac, $\mathrm{Gu}$, and in this work.

\section{Model description}

\subsection{Governing equations}

The model is based on thermodynamic gas-solid phase equilibrium theory, which assumes perfect mixing of the sulfur and gas components. As mentioned by Gu, Sun, and Heidemann, solid sulfur should be treated as single molecule $\mathrm{S}_{8} \cdot{ }^{16,25,26}$ The phase equilibrium condition of the gas-solid system requires the fugacity of gaseous sulfur to be the same as that of the solid phase, as expressed by eqn (1): ${ }^{28}$

$$
f_{\mathrm{S}_{8}}^{\mathrm{S}}(T, P)=f_{\mathrm{S}_{8}}^{\mathrm{V}}(T, P, y)
$$

\subsection{Solid phase fugacity}

The solid sulfur fugacity is related to the saturation vapor pressure of solid sulfur, as expressed by eqn (2): ${ }^{28}$

$$
f_{\mathrm{S}_{8}}^{\mathrm{s}}(T, P)=\phi_{\mathrm{S}_{8}}^{\text {sat }} P_{\mathrm{S}_{8}}^{\text {sat }} \exp \frac{V_{\mathrm{S}_{8}}^{\mathrm{S}}\left(P-P_{\mathrm{S}_{8}}^{\text {sat }}\right)}{R T}
$$

The sulfur saturation vapor pressure is always small in the gas-solid phase equilibrium system, so $\phi_{\mathrm{S}_{8}}^{\text {sat }}=1.0$ in this model. ${ }^{28}$ Shuai and Meisen ${ }^{29}$ reported regression equations of the sulfur saturation vapor pressure at different temperatures.

When $T<368 \mathrm{~K}, P_{\mathrm{S}_{8}}^{\text {sat }}$ is expressed by eqn (3):

$$
\ln P_{\mathrm{S}_{8}}^{\mathrm{sat}}=-37.566+0.1003 T
$$

When $T>368 \mathrm{~K}, P_{\mathrm{S}_{8}}^{\text {sat }}$ is expressed by eqn (4):

$$
\ln P_{\mathrm{S}_{8}}^{\text {sat }}=-30.736+0.0816 T
$$

$V_{\mathrm{S}_{8}}^{\mathrm{S}}=\frac{M}{\rho}=\frac{32.064 \times 8 \mathrm{~g} \mathrm{~mol}^{-1}}{2070 \mathrm{~kg} \mathrm{~m}^{-3}}=1.2392 \times 10^{-4} \mathrm{~m}^{3} \mathrm{~mol}^{-1}$

Using eqn (2)-(5), we can calculate the fugacity of sulfur in solid phase.

\subsection{Elemental sulfur fugacity in the gas phase}

The elemental sulfur fugacity in the gas phase can be expressed with eqn (6): ${ }^{28}$

Table 2 Critical parameters and acentric factors

\begin{tabular}{llll}
\hline Component & $\begin{array}{l}\text { Critical pressure } \\
(\mathrm{MPa})\end{array}$ & $\begin{array}{l}\text { Critical temperature } \\
(\mathrm{K})\end{array}$ & $\begin{array}{l}\text { Acentric } \\
\text { factor }\end{array}$ \\
\hline $\mathrm{S}_{8}$ & 5.2 & 1065.0 & 0.3805 \\
$\mathrm{H}_{2} \mathrm{~S}$ & 8.963 & 373.5 & 0.094 \\
$\mathrm{CO}_{2}$ & 7.383 & 304.2 & 0.224 \\
$\mathrm{CH}_{4}$ & 4.599 & 190.6 & 0.012
\end{tabular}




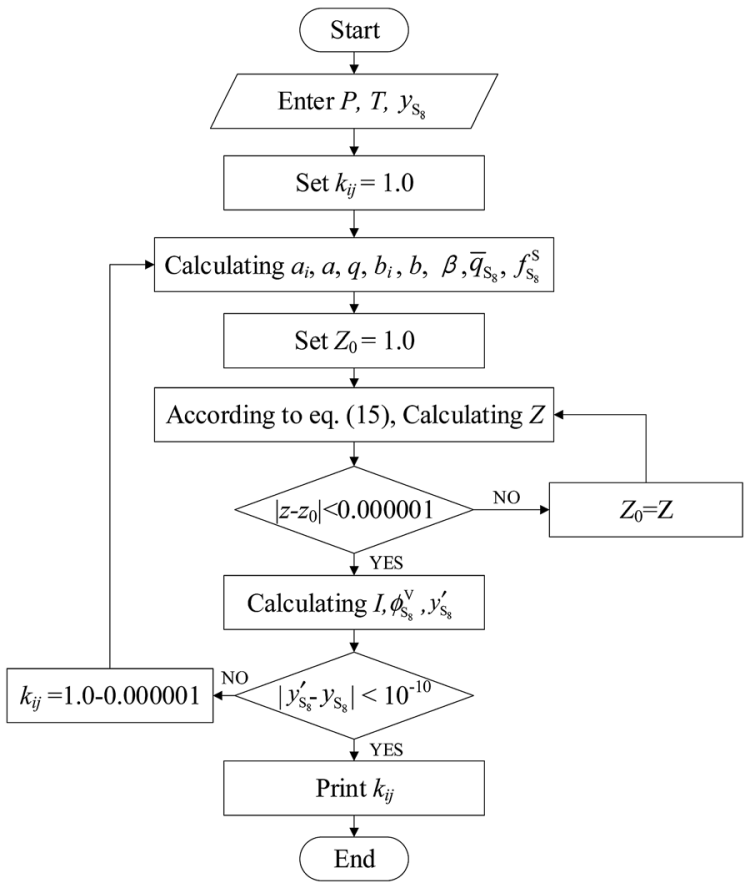

Fig. 1 Calculating diagram of $k_{\mathrm{S}_{8}}$.

$$
f_{\mathrm{S}_{8}}^{\mathrm{V}}(T, P, y)=y_{\mathrm{S}_{8}} \phi_{\mathrm{S}_{8}}^{\mathrm{V}} P
$$

2.3.1. Peng-Robinson (PR) EoS. According to eqn (6), $\phi_{\mathrm{S}_{8}}^{\mathrm{V}}$ is the key parameter for calculating the gaseous sulfur fugacity, and can be described by the PR EoS. The basic form of the PR EoS is shown in eqn (7): ${ }^{30}$

$$
P=\frac{R T}{V-b}-\frac{a}{V(V+b)+b(V-b)}
$$

where $a$ and $b$ are the parameters of PR EoS. When gas mixtures are single component, $a$ and $b$ can be expressed as follows:

$$
a=0.45724 \frac{R^{2} T_{\mathrm{c}}^{2}}{P_{\mathrm{c}}} \alpha
$$

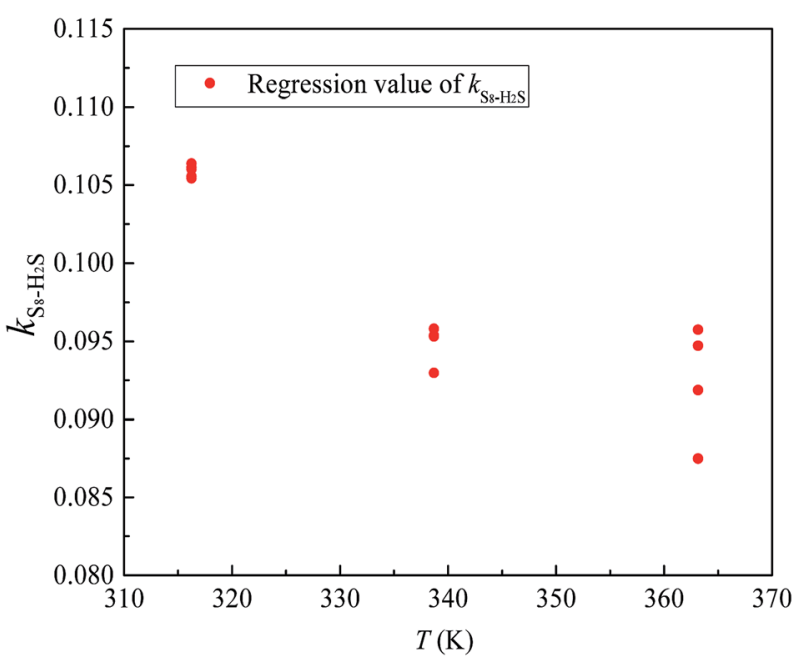

Fig. 2 The $k_{i j}$ between $\mathrm{S}_{8}$ and $\mathrm{H}_{2} \mathrm{~S}$.

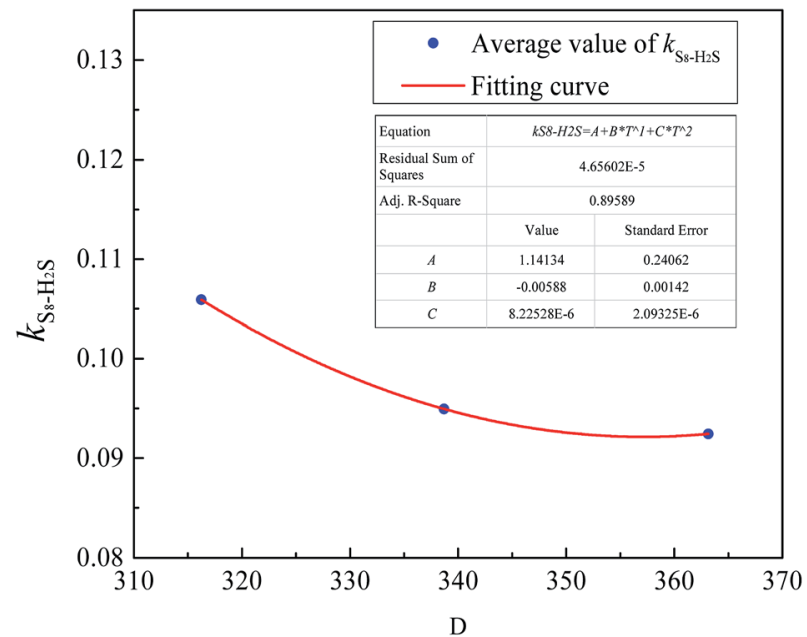

Fig. 3 The $k_{i j}$ fitting curve between $\mathrm{S}_{8}$ and $\mathrm{H}_{2} \mathrm{~S}$.

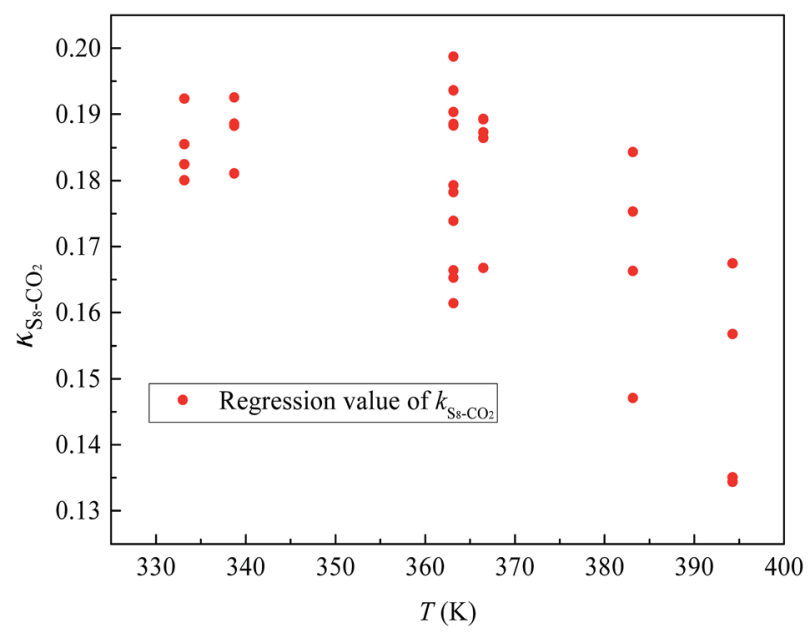

Fig. 4 The $k_{i j}$ between $\mathrm{S}_{8}$ and $\mathrm{CO}_{2}$.

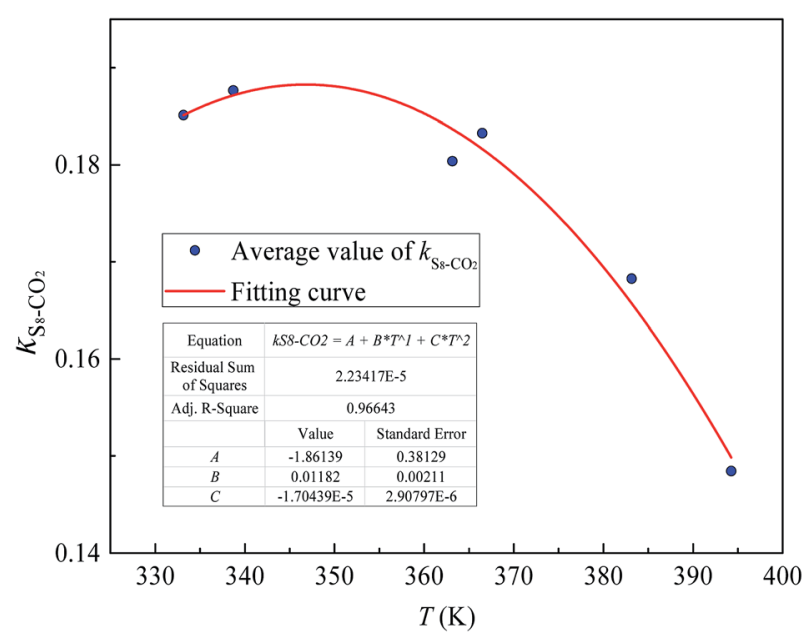

Fig. 5 The $k_{i j}$ fitting curve between $\mathrm{S}_{8}$ and $\mathrm{CO}_{2}$. 


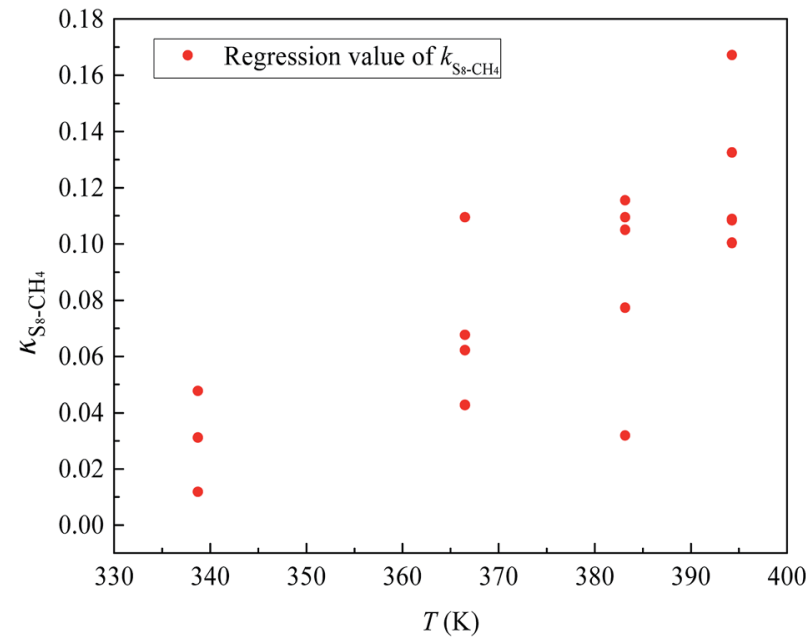

Fig. 6 The $k_{i j}$ between $\mathrm{S}_{8}$ and $\mathrm{CH}_{4}$.

$$
\begin{gathered}
b=0.07780 \frac{R T_{\mathrm{c}}}{P_{\mathrm{c}}} \\
\alpha=\left[1+\left(1-T_{\mathrm{r}}^{0.5}\right)\left(0.37464+1.54226 \omega-0.26992 \omega^{2}\right)\right]^{2} \\
T_{\mathrm{r}}=\frac{T}{T_{\mathrm{c}}}
\end{gathered}
$$

Table 2 shows the critical parameters and acentric factors of $\mathrm{S}_{8}, \mathrm{H}_{2} \mathrm{~S}, \mathrm{CO}_{2}$, and $\mathrm{CH}_{4} \cdot{ }^{27,28}$

After the solid and gas phase sulfur reach the equilibrium state, the gas phase is composed of a solvent gas component and gaseous sulfur. The $a$ and $b$ parameters need be calculated using the mixing rule according to the values of the single components. In this model, $b$ is calculated by the classic mixing rule, as follows:

$$
b=\sum_{i=1}^{n} y_{i} b_{i}
$$

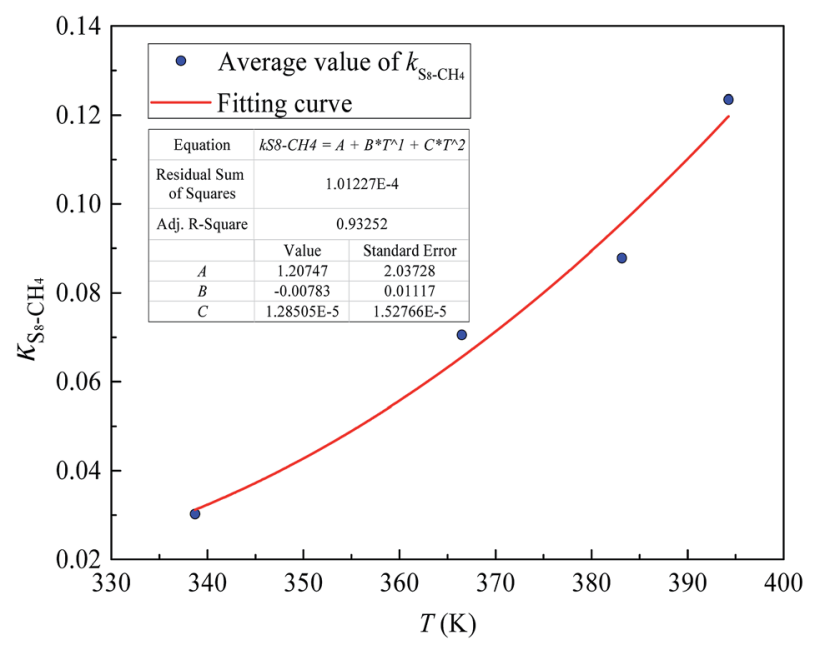

\begin{tabular}{|c|c|c|c|c|c|c|}
\hline \multirow[b]{3}{*}{ Deviation } & \multicolumn{6}{|l|}{$\underline{k_{\mathrm{S}_{8}-\mathrm{CO}_{2}}}$} \\
\hline & \multirow[b]{2}{*}{$\begin{array}{l}\text { Improved } \\
k_{\mathrm{S}_{8}-\mathrm{CO}_{2}} \\
\end{array}$} & \multirow[b]{2}{*}{0.190} & \multirow[b]{2}{*}{0.135} & \multirow{2}{*}{$\begin{array}{l}363.2 \\
\mathrm{~K} \\
0.2107\end{array}$} & \multirow{2}{*}{$\begin{array}{l}383.2 \\
\mathrm{~K} \\
0.1993\end{array}$} & \multirow[b]{2}{*}{$\begin{array}{l}0.2423- \\
21.44 / T\end{array}$} \\
\hline & & & & & & \\
\hline ARE (\%) & 1.69 & -14.57 & 111.32 & & .20 & -3.11 \\
\hline AARE (\%) & 13.12 & 16.38 & 111.36 & & 20 & 18.22 \\
\hline
\end{tabular}

Fig. 7 The $k_{i j}$ fitting curve between $\mathrm{S}_{8}$ and $\mathrm{CH}_{4}$.
Table 3 Deviation comparisons of predicting solubility in $\mathrm{CO}_{2}$ with different $k_{\mathrm{S}_{8}-\mathrm{CO}_{2}}$

The $a$ parameter of the gas mixture components will be discussed in detail in Section 3.

The fugacity coefficient of gaseous sulfur $\phi_{S_{8}}^{\mathrm{V}}$ can be expressed as:

$$
\ln \phi_{\mathrm{S}_{8}}^{\mathrm{V}}=\frac{b_{\mathrm{S}_{8}}}{b}(Z-1)-\ln (Z-\beta)-\bar{q}_{\mathrm{S}_{8}} I
$$

where

$$
b_{\mathrm{S}_{8}}=0.07780 \times R \frac{T_{\mathrm{cS}_{8}}}{P_{\mathrm{cS}}}
$$

$Z$ is calculated using

$$
Z=1+\beta-q \beta \frac{Z-\beta}{[Z+(1-\sqrt{2}) \beta][Z+(1+\sqrt{2}) \beta]}
$$

Relevant parameters in eqn (15) are expressed by eqn (16)(19):

$$
\begin{gathered}
\beta=\frac{b P}{R T} \\
q=\frac{a}{b R T} \\
\bar{q}_{\mathrm{S}_{8}}=q\left[\frac{2 \sum_{j} y_{j} a_{j \mathrm{~S}_{8}}}{a}-\frac{b_{\mathrm{S}_{8}}}{b}\right] \\
I=\frac{1}{2 \sqrt{2}} \ln \left[\frac{Z+(1+\sqrt{2}) \beta}{Z+(1-\sqrt{2}) \beta}\right]
\end{gathered}
$$

In this work, this equation was solved using the NewtonRaphson method. The elemental sulfur solubilities in $\mathrm{H}_{2} \mathrm{~S}, \mathrm{CO}_{2}$, and $\mathrm{CH}_{4}$ can be calculated easily using eqn (1)-(19).

Table 4 Deviation comparisons of predicting solubility in $\mathrm{CH}_{4}$ with different $k_{\mathrm{S}_{8}-\mathrm{CH}_{4}}$

\begin{tabular}{lcllll}
\hline & $k_{\mathrm{S}_{8}-\mathrm{CH}_{4}}$ & & & & \\
\cline { 2 - 5 } & & & & $\underline{383.2 \mathrm{~K}}$ & \\
Deviation & Improved $k_{\mathrm{S}_{8}-\mathrm{CH}_{4}}$ & 0.115 & 0.155 & 0.1345 & $377 / T$ \\
\hline ARE (\%) & 4.34 & -20.08 & -40.70 & -26.58 & -33.04 \\
AARE (\%) & 14.98 & 25.23 & 41.66 & 26.58 & 34.07
\end{tabular}




\section{Proposed method}

The classical mixing rule for $a$ is: $^{28}$

$$
a=\sum_{i=1}^{n} \sum_{j=1}^{n} y_{i} y_{j}\left(a_{i} a_{j}\right)^{0.5}\left(1-k_{i j}\right)
$$

where $k_{i j}$ are the binary interaction coefficients between $\mathrm{S}_{8}$ and the gas solvents $\left(\mathrm{H}_{2} \mathrm{~S}, \mathrm{CO}_{2}\right.$, and $\left.\mathrm{CH}_{4}\right)$. Eqn (20) shows that $k_{i j}$ are important parameters.

The reported binary interaction coefficients between $\mathrm{S}_{8}$ and $\mathrm{H}_{2} \mathrm{~S}, \mathrm{CO}_{2}$, and $\mathrm{CH}_{4}$ obtained by regression of the sulfur solubility experimental data are shown in Table 1 . The binary interaction coefficients reported by Sun and Heidemann are constant. ${ }^{25,26}$ However, as mentioned by $\mathrm{Gu}^{16}$ and Cézac, ${ }^{27}$ the binary interaction coefficients are temperature dependent. Therefore, we proposed a new mixing rule for $a$ to calculate the gaseous $\mathrm{S}_{8}$ fugacity:

$$
a=\sum_{i=1}^{n} \sum_{j=1}^{n} y_{i} y_{j}\left(a_{i} a_{j}\right)^{0.5}\left[1-\left(A+B T+C T^{2}\right)\right]
$$

Therefore,

$$
k_{i j}=A+B T+C T^{2}
$$

The $k_{i j}$ values with temperature were regressed based on the experimental data of Kennedy, Roof, Brunner, Serin, and $\mathrm{Gu},{ }^{3,13,15-17}$ and the calculated diagram is shown in Fig. 1.

According to Eslamimanesh's study of the consistency of the experimental results of sulfur solubility in $\mathrm{H}_{2} \mathrm{~S}$, only $\sim 45 \%$ of the values are reliable. ${ }^{20}$ To obtain an equation for the binary interaction coefficient between sulfur and $\mathrm{H}_{2} \mathrm{~S}$, we chose the 14 sets of experimental data at temperatures of 316.26, 338.71, and 363.15 K reported by Roof and Gu. ${ }^{\mathbf{1 3}, 16}$ Fig. 2 shows the binary interaction coefficient between $\mathrm{S}_{8}$ and $\mathrm{H}_{2} \mathrm{~S}$ calculated at temperatures of $316.26-363.15 \mathrm{~K}$. To better fit the $k_{i j}$ value, we obtained the average $k_{i j}$ values at the same temperatures shown in Fig. 3, and a new equation and fitting curve of $k_{\mathrm{S}_{8}-\mathrm{H}_{2} \mathrm{~S}}$ with temperature were obtained. The adjusted $R^{2}$ value $\left(R_{\mathrm{adj}}{ }^{2}\right)$ was 0.896 , which showed that the fitting precision was high. The new equation for the binary interaction coefficient between $S_{8}$ and $\mathrm{H}_{2} \mathrm{~S}$ is:

$$
k_{\mathrm{S}_{8}-\mathrm{H}_{2} \mathrm{~S}}=1.14134-0.00588 T+8.22528 \times 10^{-6} T^{2}
$$

Fig. 4 and 5 show the new equation and fitting curve for $k_{\mathrm{S}_{8}-\mathrm{CO}_{2}}$ in the temperature range 333.15-394.26 K $\left(R_{\mathrm{adj}}^{2}=0.966\right)$. The new equation for the binary interaction coefficient between $\mathrm{S}_{8}$ and $\mathrm{CO}_{2}$ is:

$$
k_{\mathrm{S}_{8}-\mathrm{CO}_{2}}=-1.86139+0.01182 T-1.70439 \times 10^{-5} T^{2}
$$

Fig. 6 and 7 show the new equation and fitting curve for $k_{\mathrm{S}_{8}-\mathrm{CH}_{4}}$ in the temperature range 338.71-394.26 K $\left(R_{\mathrm{adj}}^{2}=0.933\right)$. The new equation for the binary interaction coefficient between $\mathrm{S}_{8}$ and $\mathrm{CH}_{4}$ is:

$$
k_{\mathrm{S}_{8}-\mathrm{CH}_{4}}=1.20747-0.00783 T+1.28505 \times 10^{-5} T^{2}
$$

\section{Results and discussion}

\subsection{Predicting the sulfur solubility using the proposed binary interaction coefficients}

The sulfur solubility in $\mathrm{H}_{2} \mathrm{~S}$ predicted by the thermodynamic model using the proposed binary interaction coefficient between sulfur and $\mathrm{H}_{2} \mathrm{~S}$ obtained by eqn (23) is shown in Table 5 , along with the experimental results of Roof and $\mathrm{Gu}$ at temperatures of $316.26,338.71$, and $363.15 \mathrm{~K}$ and in the pressure range 7.03-32.03 $\mathrm{MPa} .^{\mathbf{1 3 , 1 6}}$ Parameter $a$ in this model was calculated with the proposed mixing rule (eqn (21)) and (23).

There are 14 sets of experimental data in Table 5. The RE, ARE, and AARE values were calculated using eqn (26)-(28):

$$
\mathrm{RE}=\frac{Z_{i}^{\text {pred }}-Z_{i}^{\text {exp }}}{Z_{i}^{\exp }}
$$

$$
\begin{aligned}
\mathrm{ARE} \% & =\frac{100}{N} \sum_{i=1}^{N}\left(\frac{Z_{i}^{\text {pred }}-Z_{i}^{\exp }}{Z_{i}^{\exp }}\right) \\
\mathrm{AARE} \% & =\frac{100}{N} \sum_{i=1}^{N}\left(\left|\frac{Z_{i}^{\text {pred }}-Z_{i}^{\exp }}{Z_{i}^{\exp }}\right|\right)
\end{aligned}
$$

Based on Table 5, the total ARE and AARE values for predicting the sulfur solubility were $6.30 \%$ and $7.90 \%$, respectively.

Fig. 8 and 9 show the ARE and AARE values of sulfur solubility in $\mathrm{H}_{2} \mathrm{~S}$ calculated from the experimental data at three different temperatures $(316.26,338.71$, and 363.15 K). Fig. 8 shows that the ARE values were positive at temperatures of $316.26,338.71$, and $363.15 \mathrm{~K}$. The lowest ARE value was $5.69 \%$ at $316.26 \mathrm{~K}$, with a highest ARE value of $7.64 \%$ at $363.15 \mathrm{~K}$. Fig. 9 shows that the greatest AARE value was $12.61 \%$ at $363.15 \mathrm{~K}$. The

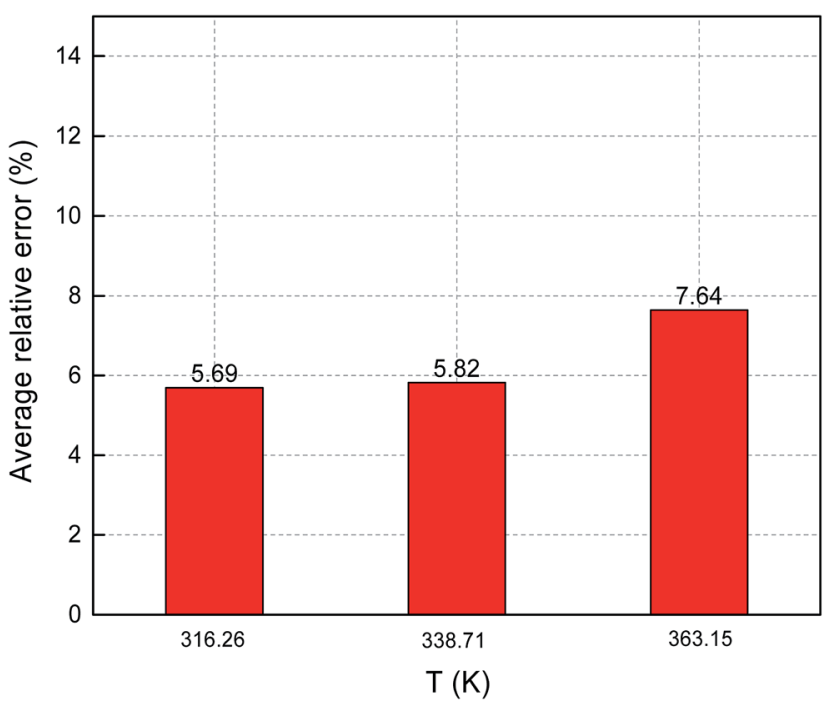

Fig. 8 ARE of sulfur solubility in $\mathrm{H}_{2} \mathrm{~S}$. 


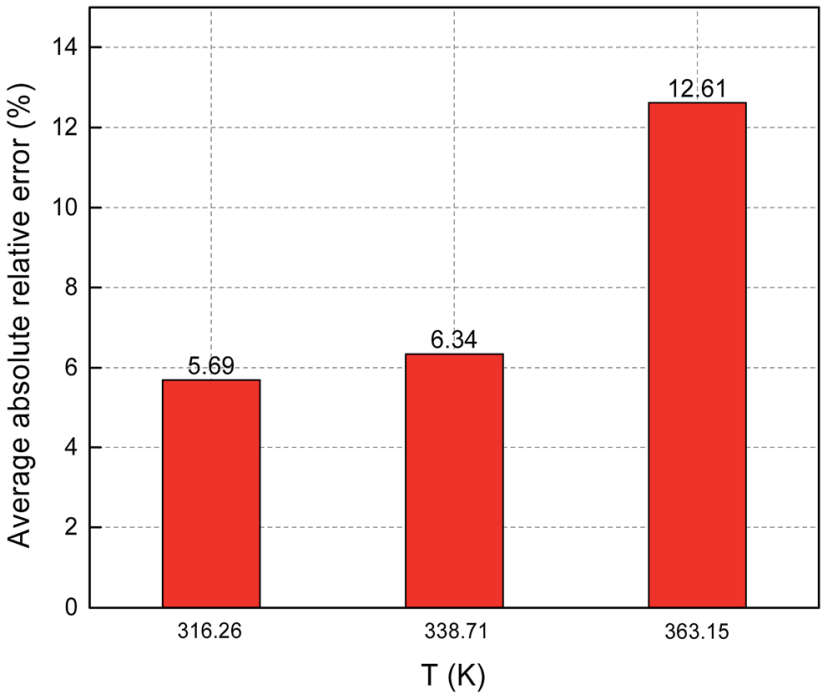

Fig. 9 AARE of sulfur solubility in $\mathrm{H}_{2} \mathrm{~S}$.

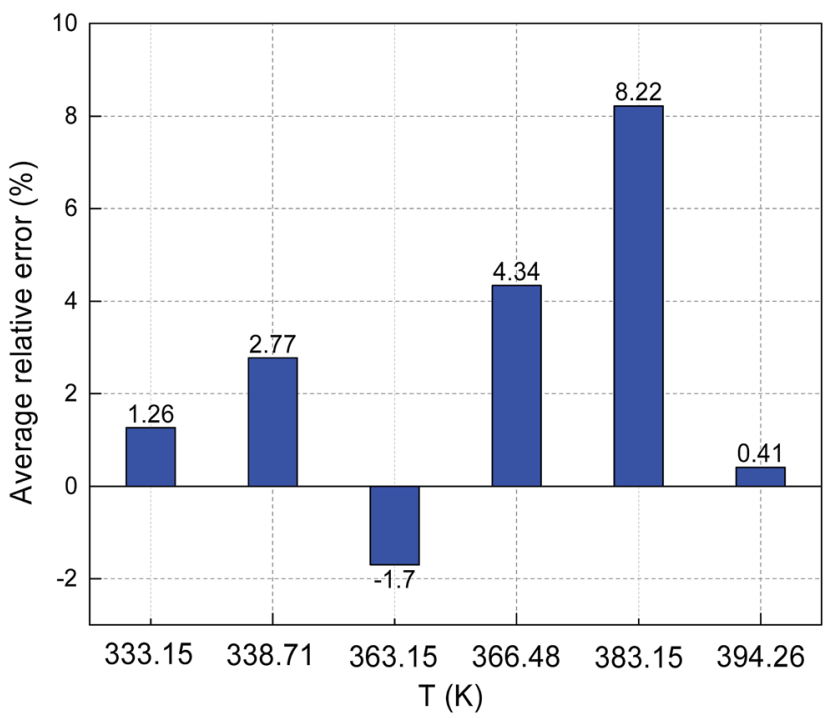

Fig. 10 ARE of sulfur solubility in $\mathrm{CO}_{2}$.

other AARE values were all below 7\%. Considering the critical temperature of $\mathrm{H}_{2} \mathrm{~S}(373.5 \mathrm{~K})$, the large deviation at $363.15 \mathrm{~K}$ could be due to the kinetic characteristics of the solvent molecule $\left(\mathrm{H}_{2} \mathrm{~S}\right)$ being influenced by external factors near the critical temperature and pressure. ${ }^{\mathbf{1 6}}$

The predicted sulfur solubility in $\mathrm{CO}_{2}$ using the proposed binary interaction coefficient, along with the experimental data of Kennedy, Gu, and Serin, in the temperature range 333.15394.26 $\mathrm{K}$ at pressures of 15.1-41.4 $\mathrm{MPa}$ are shown in Table $6 .^{3,16,17}$ Parameter $a$ with the proposed mixing rule (eqn (21)) was calculated using eqn (24). There were 32 sets of experimental data included in Table 6. Based on these calculated results, the total ARE and AARE values of the predicted sulfur solubility in $\mathrm{CO}_{2}$ were $1.69 \%$ and $13.12 \%$, respectively. Fig. 10 and 11 show the ARE and AARE values of sulfur solubility

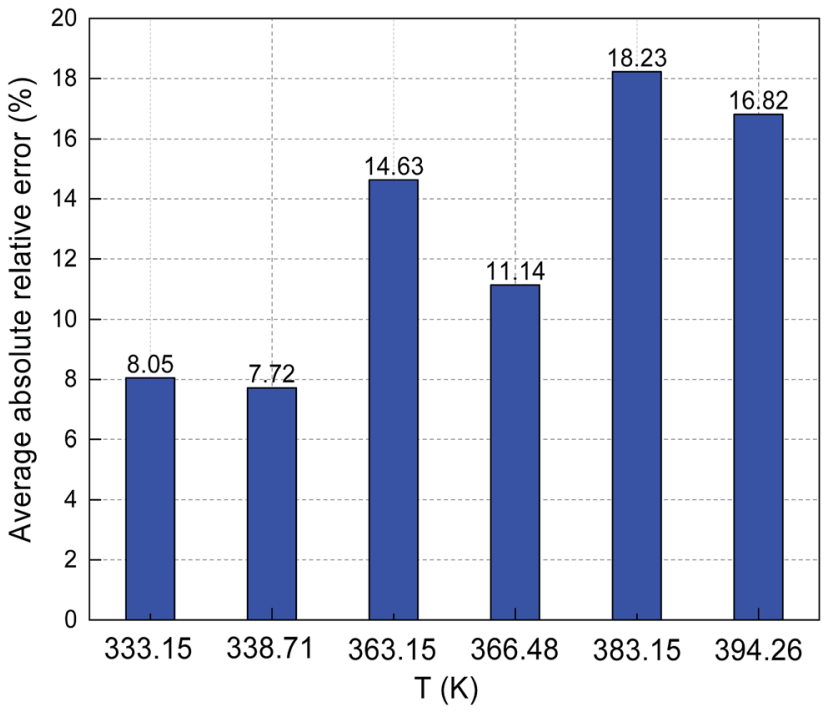

Fig. 11 AARE of sulfur solubility in $\mathrm{CO}_{2}$.

in $\mathrm{CO}_{2}$ calculated using the experimental data for six temperature ranges from 333.15-394.26 K. The lowest ARE value was $0.41 \%$ at $394.26 \mathrm{~K}$, and the highest ARE value was $8.22 \%$ at 383.15 K (Fig. 10). Fig. 11 shows that the highest AARE value was $18.23 \%$ at $383.15 \mathrm{~K}$.

The predicted sulfur solubility in $\mathrm{CH}_{4}$ using the proposed binary interaction coefficient, along with the experimental data of Kennedy and $\mathrm{Gu}$ in the temperature range 338.71-394.26 K and pressures range 6.89-41.4 MPa, are shown in Table 7.,16 Parameter $a$ with the proposed mixing rule (eqn (21)) was calculated with eqn (25). There are 17 sets of experimental data in Table 7. Based on the calculated results in Table 7, the total ARE and AARE values calculated with eqn (27) and (28) were $4.34 \%$ and $14.98 \%$, respectively. Fig. 12 and 13 show the ARE and AARE values of sulfur solubility in $\mathrm{CH}_{4}$ calculated using the

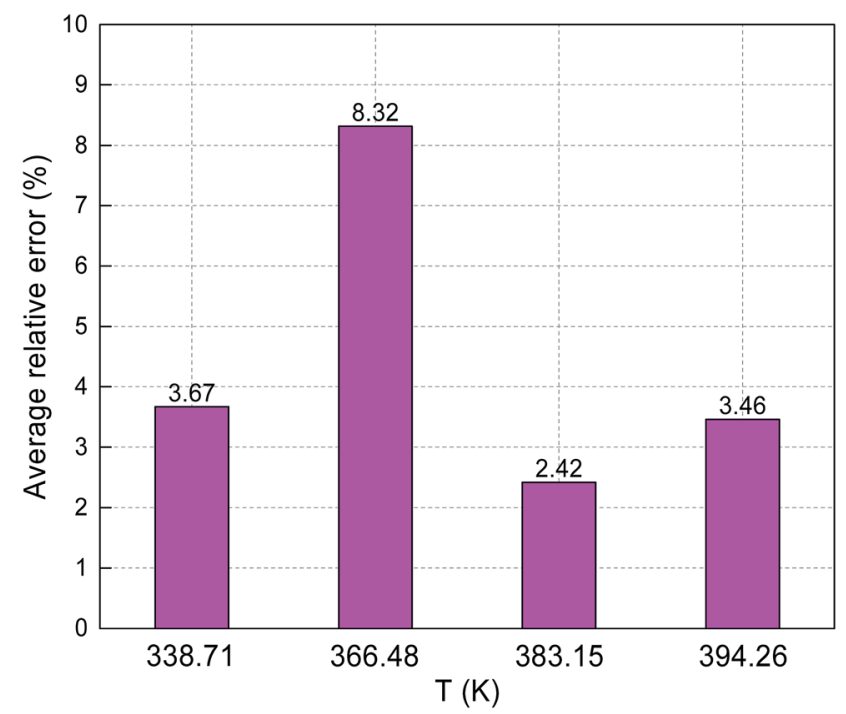

Fig. 12 ARE of sulfur solubility in $\mathrm{CH}_{4}$. 


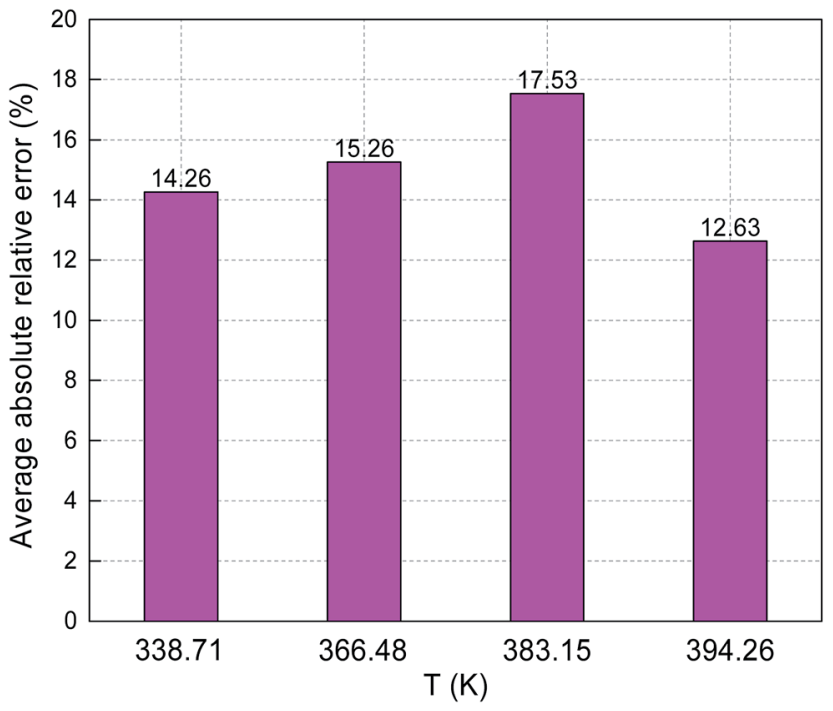

Fig. 13 AARE of sulfur solubility in $\mathrm{CH}_{4}$. experimental data for four temperatures in the range 338.71394.26 K. Fig. 12 shows that the lowest ARE value was $2.42 \%$ at 383.15 , while the highest ARE value was $8.32 \%$ at $366.48 \mathrm{~K}$. The highest AARE value was $17.53 \%$ at $383.15 \mathrm{~K}$ (Fig. 13). Combined with the results of the calculated sulfur solubilities in $\mathrm{CO}_{2}$ and $\mathrm{CH}_{4}$, the main reason for the large deviation could be that the solubility values in $\mathrm{CO}_{2}$ and $\mathrm{CH}_{4}$ are too small.

\subsection{Comparison of binary interaction coefficients}

4.2.1. Comparison of sulfur solubility in $\mathrm{H}_{2} \mathrm{~S}$ with different $\boldsymbol{k}_{\mathbf{S}_{\mathbf{8}}-\mathbf{H}_{2} \mathbf{s}}$. As mentioned above, Sun and Heidemann suggested that $k_{\mathrm{S}_{8}-\mathrm{H}_{2} \mathrm{~S}}$ is temperature independent. ${ }^{15,16}$ However, $\mathrm{Gu}$ and Cézac et al. suggested that $k_{\mathrm{S}_{8}-\mathrm{H}_{2} \mathrm{~S}}$ is temperature dependent. ${ }^{16,27}$ $\mathrm{Gu}$ determined $k_{\mathrm{S}_{8}-\mathrm{H}_{2} \mathrm{~S}}$ values at different temperatures from 316.3 to $383.2 \mathrm{~K}$ based on experimental data, and Cézac proposed a temperature-dependent $k_{\mathrm{S}_{8}-\mathrm{H}_{2} \mathrm{~S}}$ equation. ${ }^{16,27}$ Here, we compared the sulfur solubilities predicted using these different $k_{\mathrm{S}_{8}-\mathrm{H}_{2} \mathrm{~S}}$ values with our proposed $k_{\mathrm{S}_{8}-\mathrm{H}_{2} \mathrm{~S}}$ model (eqn (23)). Fig. 14

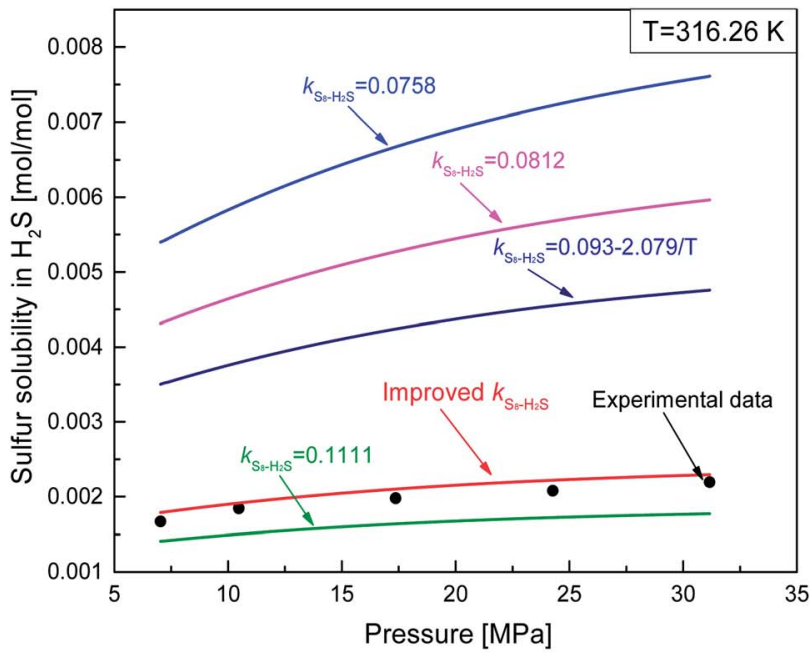

(a)

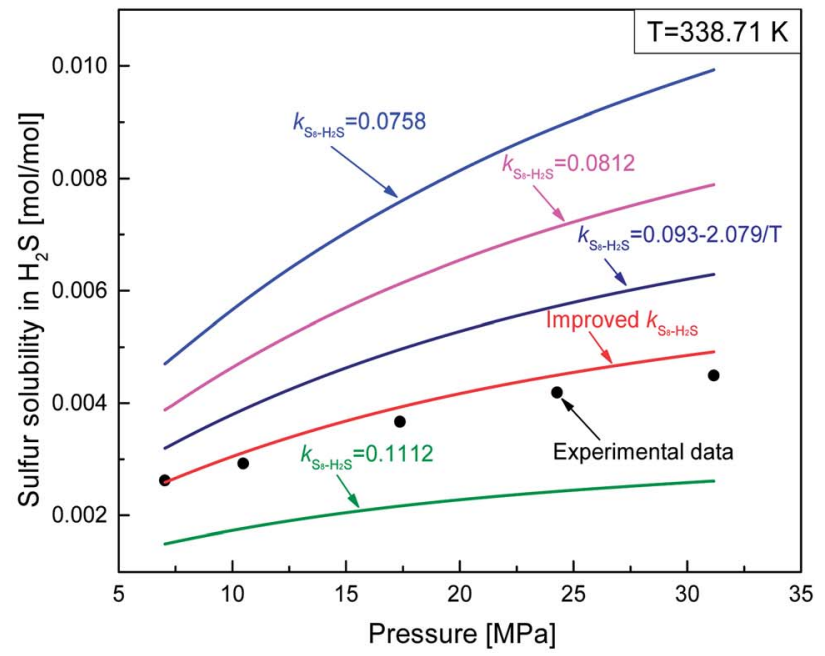

(b)

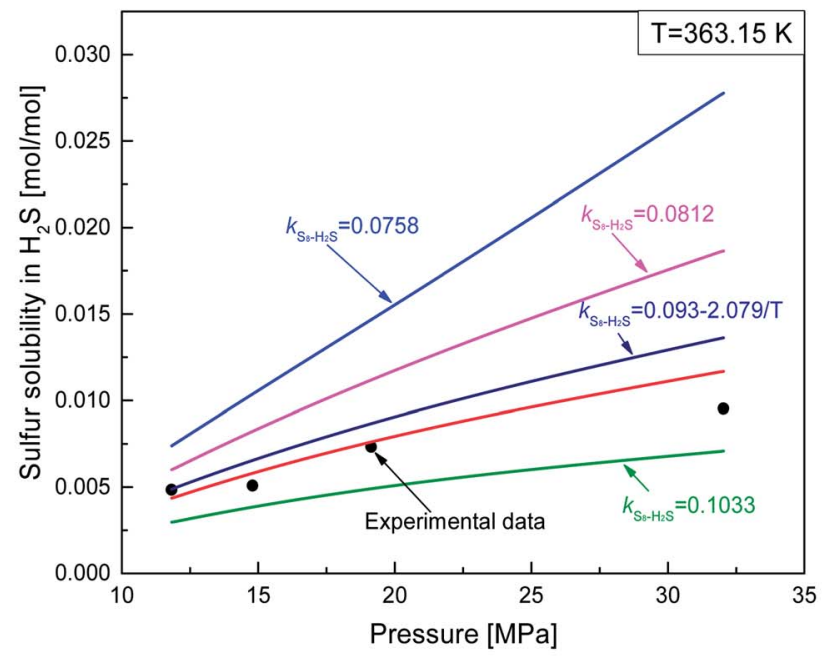

(c)

Fig. 14 Comparisons of predicting sulfur solubility in $\mathrm{H}_{2} \mathrm{~S}$ with different $k_{\mathrm{S}_{8}-\mathrm{H}_{2} \mathrm{~S}}$. 


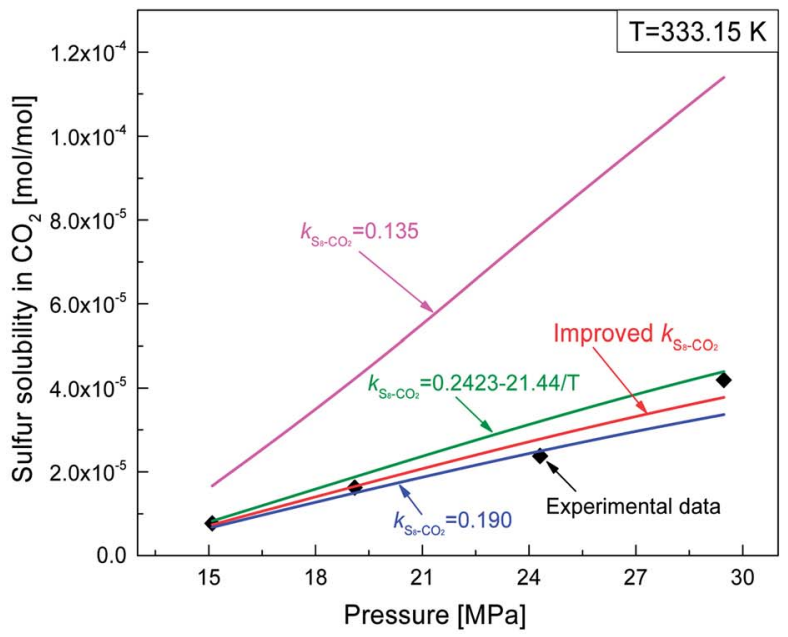

(a)

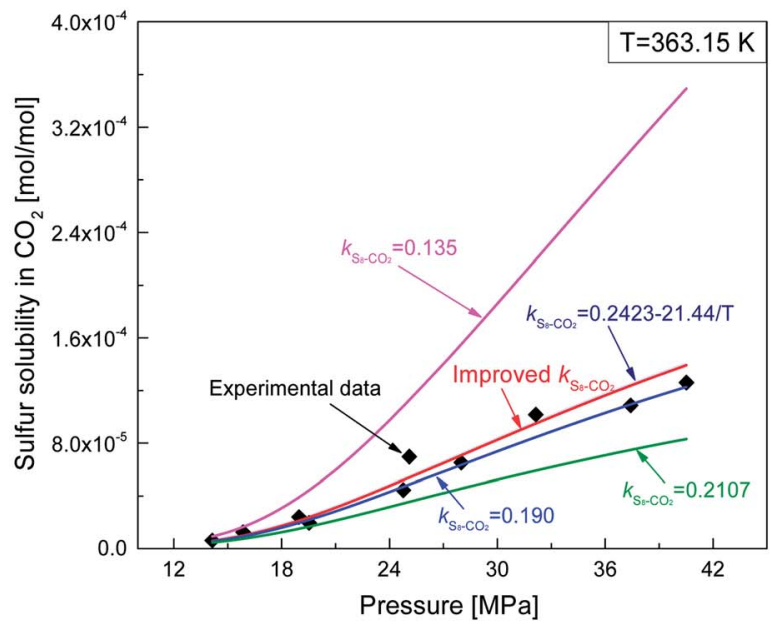

(c)

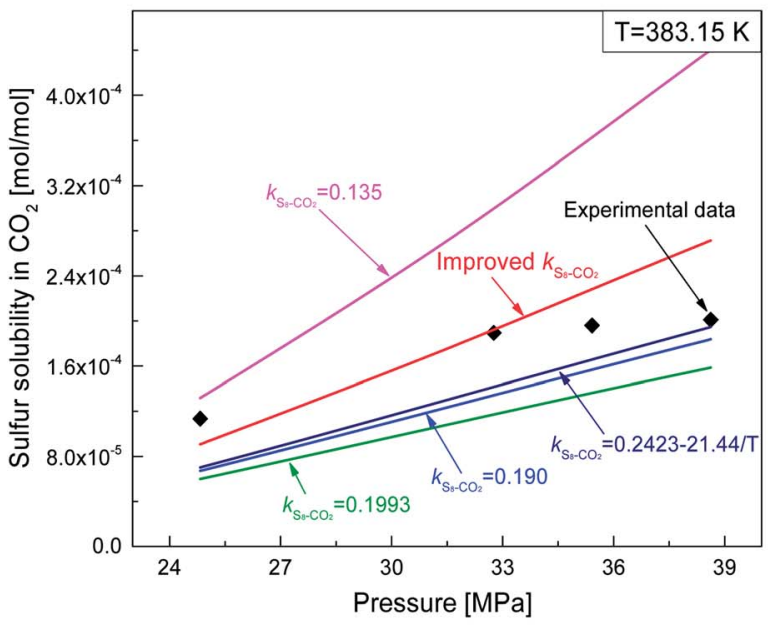

(e)

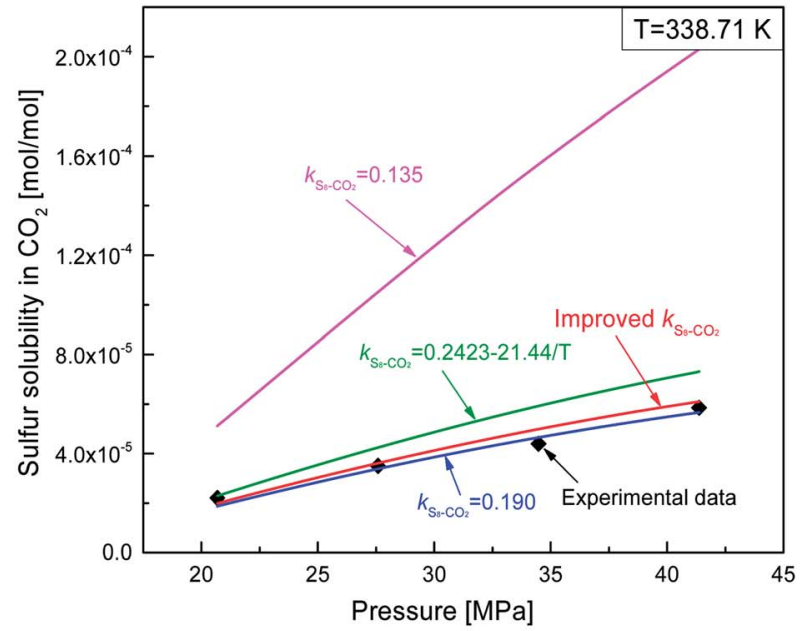

(b)

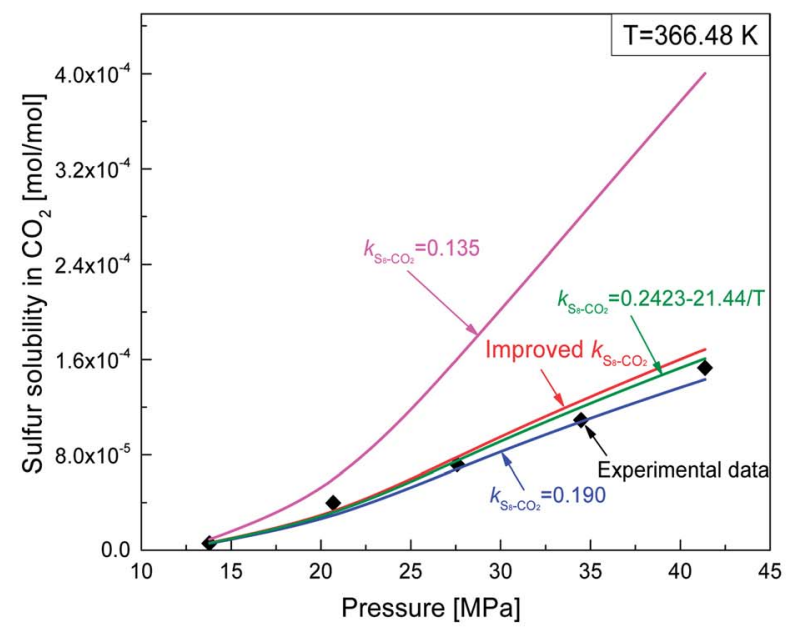

(d)

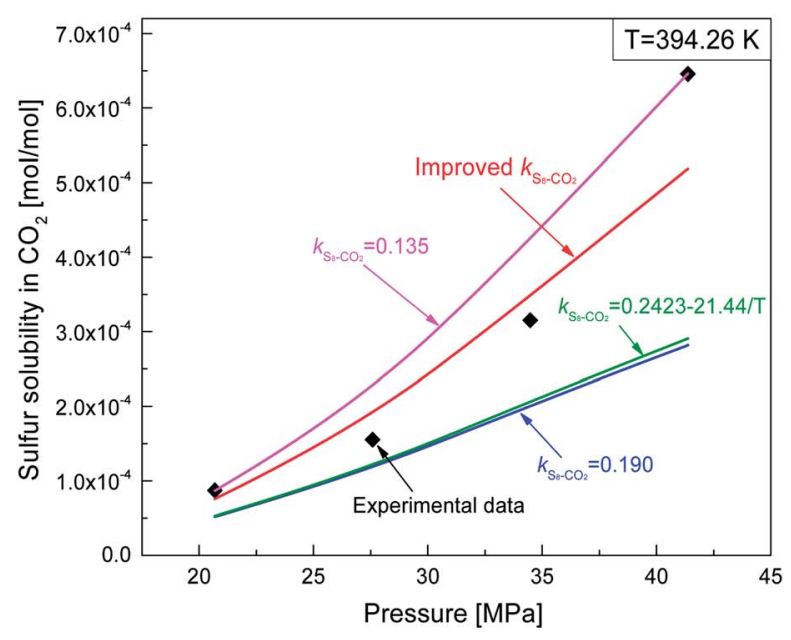

(f)

Fig. 15 Comparisons of predicting sulfur solubility in $\mathrm{CO}_{2}$ with different $k_{\mathrm{S}_{8}-\mathrm{CO}_{2}}$. 


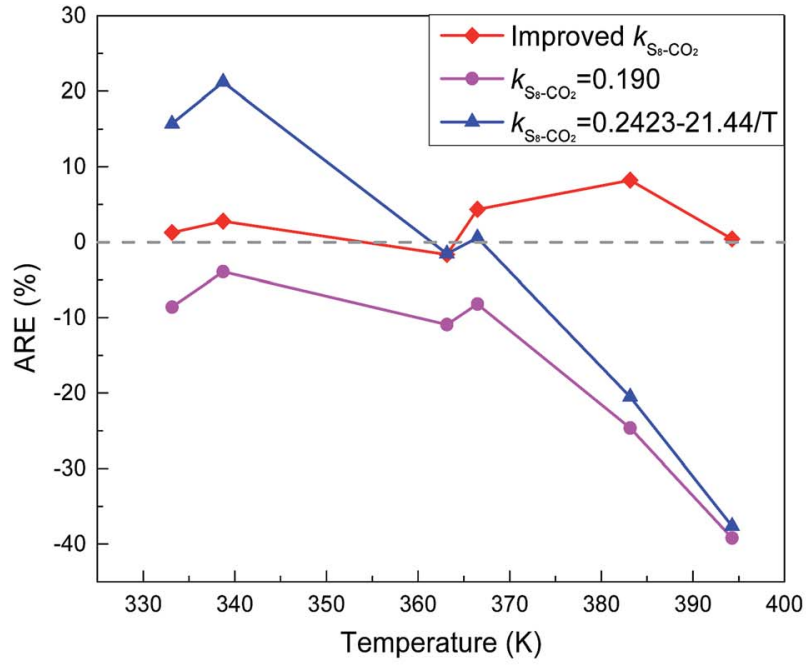

(a)

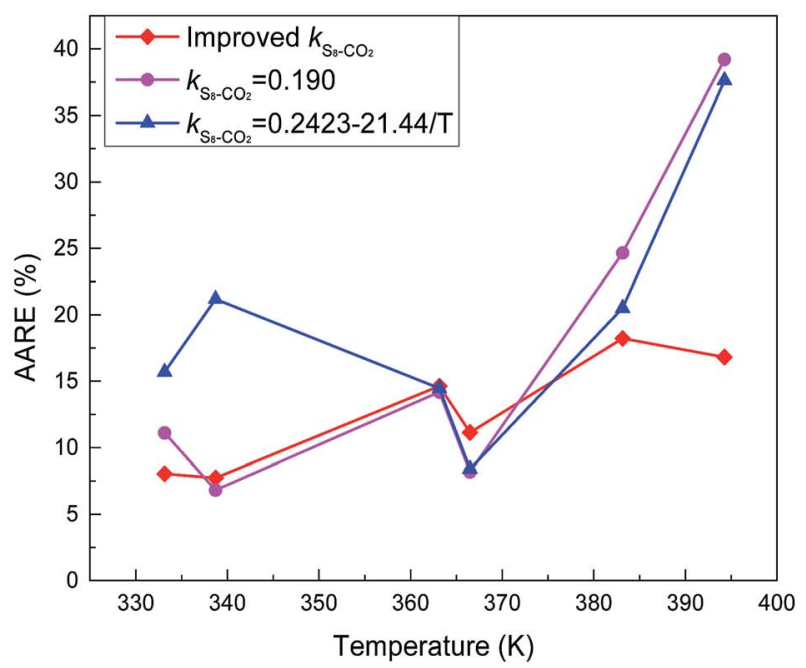

(b)

Fig. 16 The deviation of predicting solubility in $\mathrm{CO}_{2}$ with different $k_{\mathrm{S}_{8}-\mathrm{CO}_{2}}$.

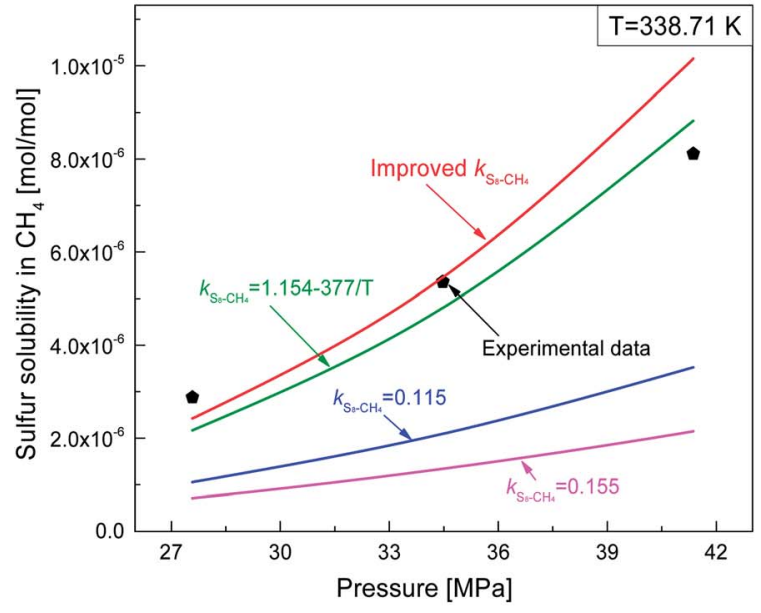

(a)

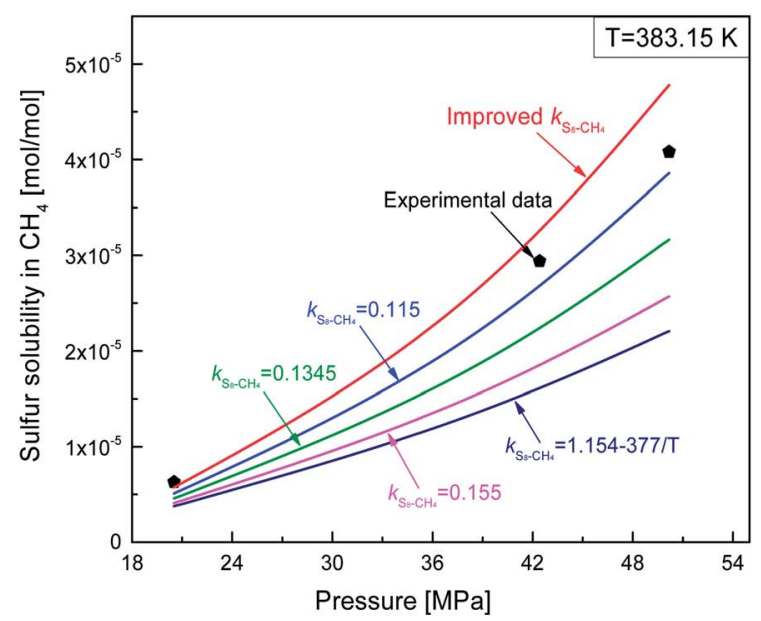

(c)

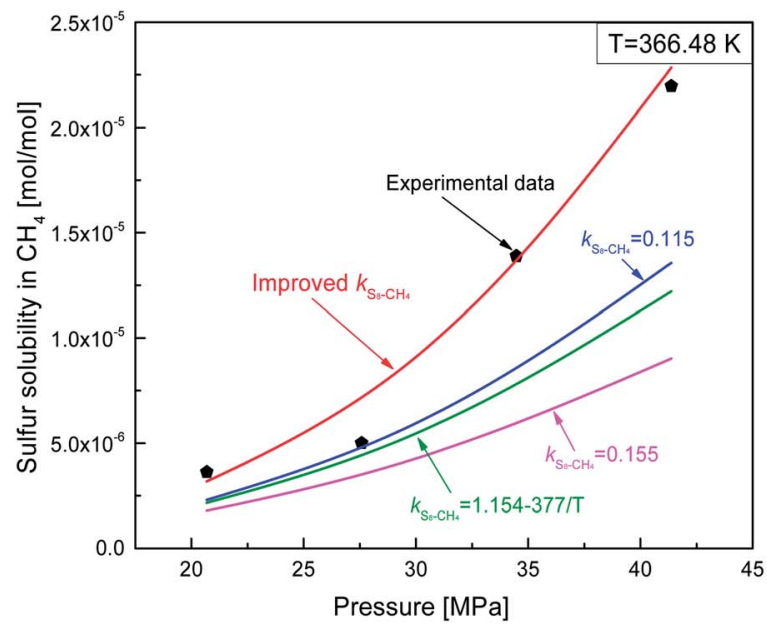

(b)

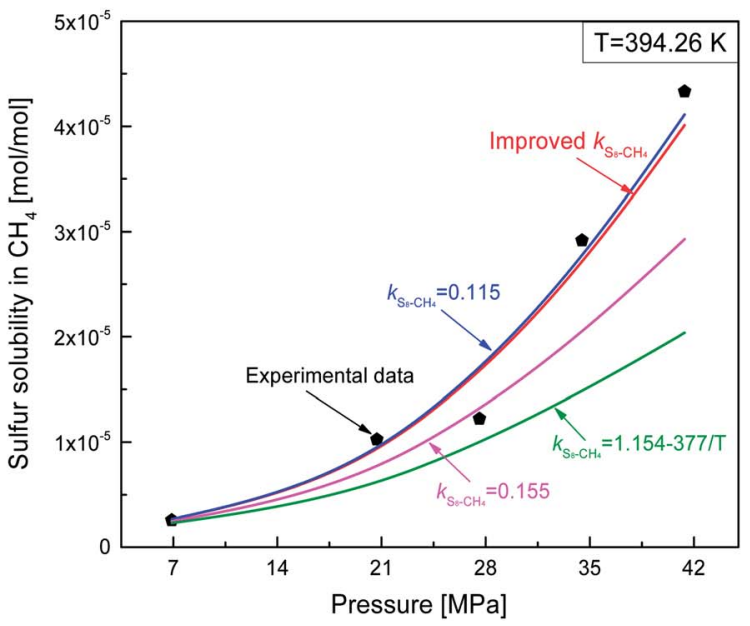

(d)

Fig. 17 Comparisons of predicting sulfur solubility in $\mathrm{CH}_{4}$ with different $k_{\mathrm{S}_{8}-\mathrm{CH}_{4}}$. 
shows that the accuracy of the predicted sulfur solubility in $\mathrm{H}_{2} \mathrm{~S}$ with the proposed $k_{\mathrm{S}_{8}-\mathrm{H}_{2} \mathrm{~S}}$ was significantly higher than those of the other four $k_{\mathrm{S}_{8}-\mathrm{H}_{2} \mathrm{~S}}$ values. At $316.26 \mathrm{~K}$, the value proposed by $\mathrm{Gu}$ was more reasonable than the three other values. The deviation in the solubility calculated with the thermodynamic model and the experimental data was relatively large using the values reported by Sun, Heidemann, and Cézac. The three values also showed that the predicted solubility was closely related to the binary interaction coefficient between sulfur and $\mathrm{H}_{2} \mathrm{~S}$. Furthermore, for the sulfur solubility in $\mathrm{H}_{2} \mathrm{~S}$, the model with the proposed $k_{\mathrm{S}_{8}-\mathrm{H}_{2} \mathrm{~S}}$ applied to temperatures ranging from 316.26 to 363.15 $\mathrm{K}$ and pressures ranging from 7.03 to $32.03 \mathrm{MPa}$.

4.2.2. Comparison of sulfur solubility in $\mathrm{CO}_{2}$ with different $\boldsymbol{k}_{\mathrm{S}_{\mathbf{8}}-\mathbf{C O}_{2}}$. Fig. 15 shows a comparison of the sulfur solubility in $\mathrm{CO}_{2}$ calculated using the thermodynamic model with five different $k_{\mathrm{S}_{8}-\mathrm{CO}_{2}}$ values at temperatures ranging from 333.15 to $394.26 \mathrm{~K}$. When $k_{\mathrm{S}_{8}-\mathrm{CO}_{2}}$ was 0.135 , the difference between the calculated sulfur solubility and the experimental data was the largest at $383.15 \mathrm{~K}$. Based on Fig. 15, the accuracy of the predicted sulfur solubility seemed to be acceptable using all of the other four $k_{\mathrm{S}_{8}-\mathrm{CO}_{2}}$ values except 0.135 .

As shown in Table 1 , the $k_{\mathrm{S}_{8}-\mathrm{CO}_{2}}$ values obtained by Sun and Heidemann were 0.190 and $0.135 .{ }^{25,26} \mathrm{Gu}$ et al. ${ }^{16}$ related the $k_{\mathrm{S}_{8}-}$ $\mathrm{CO}_{2}$ parameter to the temperature, and reported $k_{\mathrm{S}_{8}-\mathrm{CO}_{2}}$ values of 0.2107 and 0.1993 at 363.2 and $383.2 \mathrm{~K} .^{16}$ Cézac $^{27}$ suggested that $k_{\mathrm{S}_{8}-\mathrm{CO}_{2}}$ was temperature dependent and proposed an equation for calculating $k_{\mathrm{S}_{8}-\mathrm{CO}_{2}}$, as shown in Table 1 . A comparison of the total ARE and AARE values of the calculated sulfur solubility in $\mathrm{CO}_{2}$ with different $k_{\mathrm{S}_{8}-\mathrm{CO}_{2}}$ values is shown in Table 3. From Table 3 , the deviations of the solubility values calculated using the proposed $k_{\mathrm{S}_{8}-\mathrm{CO}_{2}}$ from the experimental data were smaller than those using the other four $k_{\mathrm{S}_{8}-\mathrm{CO}_{2}}$ values.

A comparison of the ARE and AARE values for different $k_{\mathrm{S}_{8}-}$ $\mathrm{CO}_{2}$ at temperatures of 333.15 to $394.26 \mathrm{~K}$ is shown in Fig. 16. Fig. 16(a) shows that ARE is the closest to $0 \%$ with the proposed $k_{\mathrm{S}_{8}-\mathrm{CO}_{2}}, \mathrm{ARE}<0$ when $k_{\mathrm{S}_{8}-\mathrm{CO}_{2}}$ is 0.190 , and ARE is both negative and positive for the $k_{\mathrm{S}_{8}-\mathrm{CO}_{2}}$ reported by Cézac. ${ }^{27} \mathrm{Using}$ the $k_{\mathrm{S}_{8}-\mathrm{CO}_{2}}$ and $k_{\mathrm{S}_{8}-\mathrm{CO}_{2}}$ values reported by Cézac, ${ }^{27}$ the ARE values were $-1.67 \%$ and $-1.57 \%$ at $363.15 \mathrm{~K}$, and $4.34 \%$ and $0.55 \%$ at $366.48 \mathrm{~K}$, respectively.

As shown Fig. 16(b), the AARE values were smaller using the proposed $k_{\mathrm{S}_{8}-\mathrm{CO}_{2}}$ than using the other two $k_{\mathrm{S}_{8}-\mathrm{CO}_{2}}$ values. At 338.71 $\mathrm{K}$, the AARE values were $7.72 \%$ and $6.82 \%$ using the proposed $k_{\mathrm{S}_{8}-}$ $\mathrm{CO}_{2}$ and $k_{\mathrm{S}_{8}-\mathrm{CO}_{2}}=0.190$, respectively. Using the proposed $k_{\mathrm{S}_{8}-\mathrm{CO}_{2}}$, the $k_{\mathrm{S}_{8}-\mathrm{CO}_{2}}$ reported by Sun, and the $k_{\mathrm{S}_{8}-\mathrm{CO}_{2}}$ reported by Cézac, the AARE values were $14.63 \%, 14.18 \%$, and $14.64 \%$ at $363.15 \mathrm{~K}$, and $11.14 \%, 8.18 \%$, and $8.40 \%$ at $366.48 \mathrm{~K}$, respectively. Fig. 16 shows that the accuracy of the predicted solubility using $k_{\mathrm{S}_{8}-\mathrm{CO}_{2}}$ reported by Cézac was higher than that using the $k_{\mathrm{S}_{8}-\mathrm{CO}_{2}}$ proposed in this paper at 363.15 and $366.48 \mathrm{~K}$. However, the total deviation was still the lowest using the proposed binary interaction coefficient between sulfur and $\mathrm{CO}_{2}$ (Table 6 and Fig. 16).

4.2.3. Comparison of sulfur solubility in $\mathrm{CH}_{4}$ with different $\boldsymbol{k}_{\mathrm{S}_{\mathbf{8}}-\mathbf{C H}_{4}}$. As shown in Table 1 , the $k_{\mathrm{S}_{8}-\mathbf{C H}_{4}}$ values reported by Heidemann and Sun are 0.155 and 0.115 , respectively. ${ }^{25,26} \mathrm{Gu}$ et al. related $k_{\mathrm{S}_{8}-\mathrm{CH}_{4}}$ to temperature, but only reported the $k_{\mathrm{S}_{8}-\mathrm{CH}_{4}}$ value at $383.2 \mathrm{~K}^{16}$ Cézac et $a{ }^{12}{ }^{27}$ proposed a temperature- dependent equation for calculating $k_{\mathrm{S}_{8}-\mathrm{CH}_{4}}$ (Table 1). The total ARE and AARE values of the calculated sulfur solubility in $\mathrm{CH}_{4}$ using the different values of $k_{\mathrm{S}_{8}-\mathrm{CH}_{4}}$ are shown in Table 4 . The lowest ARE and AARE values of $4.34 \%$ and $14.98 \%$ were obtained using the proposed $k_{\mathrm{S}_{8}-\mathrm{CH}_{4}}$. When $k_{\mathrm{S}_{8}-\mathrm{CH}_{4}}=0.155$, the deviations between the calculated solubility values and the experimental data were the largest. From Table 4 , the deviations between the solubility values calculated using the proposed $k_{\mathrm{S}_{8^{-}}}$ $\mathrm{CH}_{4}$ and the experimental data were smaller than those using the other four $k_{\mathrm{S}_{8}-\mathrm{CH}_{4}}$.

Fig. 17 shows a comparison of the predicted sulfur solubility in $\mathrm{CH}_{4}$ using the thermodynamic model with five different $k_{\mathrm{S}_{8}-}$ $\mathrm{CH}_{4}$ at temperatures ranging from 338.71 to $394.26 \mathrm{~K}$. Fig. 17(c) shows the calculated sulfur solubility in $\mathrm{CH}_{4}$ with five different $k_{\mathrm{S}_{8}-\mathrm{CH}_{4}}$ at $383.15 \mathrm{~K}$, because $k_{\mathrm{S}_{8}-\mathrm{CH}_{4}}=0.1345$ reported by Gu was only suitable at $383.2 \mathrm{~K}$. Therefore, Fig. 17(a), (b), and (d) only show the predicted solubility with four different $k_{\mathrm{S}_{8}-\mathrm{CH}_{4}}$.

As shown in Fig. 17, the predicted solubility values were negative, except for that calculated using the proposed $k_{\mathrm{S}_{8}-\mathrm{CH}_{4}}$. When $k_{\mathrm{S}_{8}-\mathrm{CH}_{4}}=0.115$ at $394.26 \mathrm{~K}$, the calculated solubility in $\mathrm{CH}_{4}$ was close to the experimental data (Fig. 17 (d)). Using $k_{\mathrm{S}_{8}-\mathrm{CH}_{4}}=$ 0.115 and the proposed $k_{\mathrm{S}_{8}-\mathrm{CH}_{4}}$, the ARE values were $5.25 \%$ and $3.46 \%$, while the AARE values were $12.11 \%$ and $12.63 \%$, respectively. This indicated that the predicted solubility at $394.26 \mathrm{~K}$ using the $k_{\mathrm{S}_{8}-\mathrm{CH}_{4}}$ value reported by Sun was also acceptable. ${ }^{26}$

\section{Conclusions}

We have proposed new three-parameter equations to calculate the binary interaction coefficients between sulfur and $\mathrm{H}_{2} \mathrm{~S}, \mathrm{CO}_{2}$, and $\mathrm{CH}_{4}$. The parameters in these three equations were obtained by regression of the experimental sulfur solubility data in $\mathrm{H}_{2} \mathrm{~S}$, $\mathrm{CO}_{2}$, and $\mathrm{CH}_{4}$. The relationship between the binary interaction coefficients and temperature was quadratic. The binary interaction coefficients $k_{\mathrm{S}_{8}-\mathrm{H}_{2} \mathrm{~S}}, k_{\mathrm{S}_{8}-\mathrm{CO}_{2}}$, and $k_{\mathrm{S}_{8}-\mathrm{CH}_{4}}$ were expressed by eqn (23)-(25), and the $R_{\mathrm{adj}}{ }^{2}$ values of the new fitting equations were $0.896,0.966$, and 0.933 , respectively, which indicated that the new three-parameter equations were reliable.

By comparing the experimental solubility data with the solubility results predicted using the binary interaction coefficients proposed by this work and those reported by Sun, Heidemann, Gu, and Cézac, the total ARE and AARE values were significantly smaller when using the proposed binary interaction coefficients than those when using the other four. However, the accuracy of the predicted sulfur solubility in $\mathrm{CO}_{2}$ using $k_{\mathrm{S}_{\mathrm{s}^{-}}}$ $\mathrm{CO}_{2}$ reported by Cézac was slightly higher than that using $k_{\mathrm{S}_{8}-\mathrm{CO}_{2}}$ proposed in this article at temperatures of 363.15 and $366.48 \mathrm{~K}$. Furthermore, the calculated solubility in $\mathrm{CH}_{4}$ using $k_{\mathrm{S}_{8}-\mathrm{CH}_{4}}$ reported by Sun was acceptable.

In general, the predicted results were satisfactory considering the ARE and AARE values obtained using the proposed binary interaction coefficients. The accuracies of the predicted sulfur solubilities in $\mathrm{H}_{2} \mathrm{~S}, \mathrm{CO}_{2}$, and $\mathrm{CH}_{4}$ using the thermodynamic model with the proposed binary interaction coefficients based on the PR EoS were greatly improved, and the thermodynamic model was suitable for a wide range of temperatures and pressures. 


\section{Conflicts of interest}

There are no conflicts to declare.

\section{Appendix}

Table 5 Elemental sulfur solubility in $\mathrm{H}_{2} \mathrm{~S}$

\begin{tabular}{|c|c|c|c|c|}
\hline$T / \mathrm{K}$ & $P / \mathrm{MPa}$ & $\begin{array}{l}\text { Solubility (experiment)/ } \\
\mathrm{mol} \mathrm{mol}^{-1}\end{array}$ & $\begin{array}{l}\text { Solubility (this } \\
\text { model) } / \mathrm{mol} \mathrm{mol}^{-1}\end{array}$ & $\begin{array}{l}\text { Relative } \\
\text { error }\end{array}$ \\
\hline \multirow[t]{5}{*}{316.26} & 7.03 & 0.001669 & 0.001790 & 0.0722 \\
\hline & 10.48 & 0.001846 & 0.001915 & 0.0373 \\
\hline & 17.37 & 0.001977 & 0.002099 & 0.0619 \\
\hline & 24.27 & 0.002078 & 0.002220 & 0.0682 \\
\hline & 31.16 & 0.002196 & 0.002294 & 0.0448 \\
\hline \multirow[t]{5}{*}{338.71} & 7.03 & 0.00262 & 0.002586 & -0.0129 \\
\hline & 10.48 & 0.002926 & 0.003120 & 0.0662 \\
\hline & 17.37 & 0.00367 & 0.003927 & 0.0701 \\
\hline & 24.27 & 0.004189 & 0.004502 & 0.0747 \\
\hline & 31.16 & 0.004494 & 0.004913 & 0.0932 \\
\hline \multirow[t]{4}{*}{363.15} & 11.83 & 0.004832 & 0.004352 & -0.0993 \\
\hline & 14.79 & 0.005081 & 0.005789 & 0.1393 \\
\hline & 19.14 & 0.007313 & 0.007613 & 0.0410 \\
\hline & 32.03 & 0.009523 & 0.011664 & 0.2248 \\
\hline
\end{tabular}

\begin{tabular}{|c|c|c|c|c|c|}
\hline$T / \mathrm{K}$ & $P / \mathrm{MPa}$ & $\begin{array}{l}\text { Solubility (experiment)/ } \\
\mathrm{mol} \mathrm{mol}^{-1}\end{array}$ & $\begin{array}{l}\text { Solubility (this } \\
\text { model) } / \mathrm{mol} \mathrm{mol}^{-1}\end{array}$ & $\begin{array}{l}\text { Relative } \\
\text { error }\end{array}$ & AARE \\
\hline \multirow[t]{4}{*}{333.15} & 15.10 & $7.682 \times 10^{-6}$ & $7.400 \times 10^{-6}$ & -0.0368 & \multirow{4}{*}{ Roman symbols } \\
\hline & 19.10 & $1.624 \times 10^{-5}$ & $1.650 \times 10^{-5}$ & 0.0144 & \\
\hline & 24.31 & $2.377 \times 10^{-5}$ & $2.790 \times 10^{-5}$ & 0.1718 & \\
\hline & 29.47 & $4.193 \times 10^{-5}$ & $3.780 \times 10^{-5}$ & -0.0991 & \\
\hline \multirow[t]{4}{*}{338.71} & 20.68 & $2.205 \times 10^{-5}$ & $1.990 \times 10^{-5}$ & -0.0991 & \multirow{4}{*}{$\begin{array}{l}f_{\mathrm{S}_{8}}^{\mathrm{S}} \\
f_{\mathrm{S}_{8}}^{\mathrm{V}}\end{array}$} \\
\hline & 27.58 & $3.504 \times 10^{-5}$ & $3.610 \times 10^{-5}$ & 0.0316 & \\
\hline & 34.47 & $4.395 \times 10^{-5}$ & $4.990 \times 10^{-5}$ & 0.1351 & \\
\hline & 41.37 & $5.851 \times 10^{-5}$ & $6.100 \times 10^{-5}$ & 0.0431 & \\
\hline \multirow[t]{11}{*}{363.15} & 15.86 & $1.252 \times 10^{-5}$ & $9.960 \times 10^{-6}$ & -0.2044 & \multirow{2}{*}{$\begin{array}{l}P \\
T\end{array}$} \\
\hline & 19.53 & $1.961 \times 10^{-5}$ & $2.390 \times 10^{-5}$ & 0.2174 & \\
\hline & 24.76 & $4.439 \times 10^{-5}$ & $5.190 \times 10^{-5}$ & 0.1684 & $y$ \\
\hline & 27.99 & $6.528 \times 10^{-5}$ & $7.080 \times 10^{-5}$ & 0.0845 & $\phi_{\mathrm{S}}^{\mathrm{sat}}$ \\
\hline & 14.14 & $6.200 \times 10^{-6}$ & $5.920 \times 10^{-6}$ & -0.0455 & $R$ \\
\hline & 18.97 & $2.400 \times 10^{-5}$ & $2.130 \times 10^{-5}$ & -0.1109 & \multirow{2}{*}{$\begin{array}{l}K \\
P_{\mathrm{S}_{8}}^{\text {sat }}\end{array}$} \\
\hline & 25.10 & $6.970 \times 10^{-5}$ & $5.380 \times 10^{-5}$ & -0.2276 & \\
\hline & 25.10 & $7.090 \times 10^{-5}$ & $5.380 \times 10^{-5}$ & -0.2407 & \multirow{4}{*}{$\begin{array}{l}V_{\mathrm{S}_{8}}^{\mathrm{sat}} \\
y_{\mathrm{S}_{8}}\end{array}$} \\
\hline & 32.14 & $1.017 \times 10^{-4}$ & $9.490 \times 10^{-5}$ & -0.0673 & \\
\hline & 37.41 & $1.087 \times 10^{-4}$ & $1.236 \times 10^{-4}$ & 0.1374 & \\
\hline & 40.52 & $1.260 \times 10^{-4}$ & $1.392 \times 10^{-4}$ & 0.1051 & \\
\hline \multirow[t]{5}{*}{366.48} & 13.79 & $5.805 \times 10^{-6}$ & $6.110 \times 10^{-6}$ & 0.0529 & $\begin{array}{l}4 \mathrm{~S}_{8} \\
V\end{array}$ \\
\hline & 20.68 & $3.966 \times 10^{-5}$ & $3.290 \times 10^{-5}$ & -0.1700 & $T_{c}$ \\
\hline & 27.58 & $7.193 \times 10^{-5}$ & $7.800 \times 10^{-5}$ & 0.0843 & $P$ \\
\hline & 34.47 & $1.091 \times 10^{-4}$ & $1.253 \times 10^{-4}$ & 0.1487 & $P_{\mathrm{c}}$ \\
\hline & 41.37 & $1.530 \times 10^{-4}$ & $1.685 \times 10^{-4}$ & 0.1012 & $\omega$ \\
\hline \multirow[t]{4}{*}{383.15} & 24.83 & $1.135 \times 10^{-4}$ & $9.080 \times 10^{-5}$ & -0.2001 & $T_{\mathrm{r}}$ \\
\hline & 32.76 & $1.894 \times 10^{-4}$ & $1.921 \times 10^{-4}$ & 0.0142 & $Z$ \\
\hline & 35.41 & $1.960 \times 10^{-4}$ & $2.281 \times 10^{-4}$ & 0.1640 & $n$ \\
\hline & 38.62 & $2.009 \times 10^{-4}$ & $2.714 \times 10^{-4}$ & 0.3509 & $v_{i}$ \\
\hline \multirow[t]{4}{*}{394.26} & 20.68 & $8.716 \times 10^{-5}$ & $7.570 \times 10^{-5}$ & -0.1317 & \multirow{4}{*}{$y_{j}$} \\
\hline & 27.58 & $1.554 \times 10^{-4}$ & $1.924 \times 10^{-4}$ & 0.2382 & \\
\hline & 34.47 & $3.153 \times 10^{-4}$ & $3.489 \times 10^{-4}$ & 0.1064 & \\
\hline & 41.37 & $6.457 \times 10^{-4}$ & $5.188 \times 10^{-4}$ & -0.1966 & \\
\hline
\end{tabular}

\section{Abbreviations}

Table 6 Elemental sulfur solubility in $\mathrm{CO}_{2}$

EoS

RE

ARE

Table 7 Elemental sulfur solubility in $\mathrm{CH}_{4}$

\begin{tabular}{lllll}
\hline & & $\begin{array}{l}\text { Solubility (experiment) } / \\
\mathrm{mol} \mathrm{mol}^{-1}\end{array}$ & $\begin{array}{l}\text { Solubility (this } \\
\text { model) } / \mathrm{mol} \mathrm{mol}^{-1}\end{array}$ & $\begin{array}{l}\text { Relative } \\
\text { error }\end{array}$ \\
\hline 338.71 & 27.5792 & $2.882 \times 10^{-6}$ & $2.420 \times 10^{-6}$ & -0.1588 \\
& 34.474 & $5.357 \times 10^{-6}$ & $5.450 \times 10^{-6}$ & 0.0178 \\
& 41.3688 & $8.113 \times 10^{-6}$ & $1.020 \times 10^{-5}$ & 0.2511 \\
366.48 & 20.6844 & $3.623 \times 10^{-6}$ & $3.170 \times 10^{-6}$ & -0.1241 \\
& 27.5792 & $5.008 \times 10^{-6}$ & $7.170 \times 10^{-6}$ & 0.4316 \\
& 34.474 & $1.389 \times 10^{-5}$ & $1.370 \times 10^{-5}$ & -0.0146 \\
383.15 & 41.3688 & $2.196 \times 10^{-5}$ & $2.280 \times 10^{-5}$ & 0.0400 \\
& 20.517 & $8.100 \times 10^{-6}$ & $5.750 \times 10^{-6}$ & -0.2903 \\
& 20.517 & $6.300 \times 10^{-6}$ & $5.750 \times 10^{-6}$ & -0.0875 \\
& 42.414 & $2.940 \times 10^{-5}$ & $3.260 \times 10^{-5}$ & 0.1077 \\
& 42.414 & $2.670 \times 10^{-5}$ & $3.260 \times 10^{-5}$ & 0.2197 \\
& 50.172 & $4.080 \times 10^{-5}$ & $4.780 \times 10^{-5}$ & 0.1711 \\
394.26 & 6.8948 & $2.588 \times 10^{-6}$ & $2.660 \times 10^{-6}$ & 0.0282 \\
& 20.6844 & $1.027 \times 10^{-5}$ & $9.380 \times 10^{-6}$ & -0.0861 \\
& 27.5792 & $1.223 \times 10^{-5}$ & $1.680 \times 10^{-5}$ & 0.3742 \\
& 34.474 & $2.918 \times 10^{-5}$ & $2.720 \times 10^{-5}$ & -0.0695 \\
& 41.3688 & $4.331 \times 10^{-5}$ & $4.010 \times 10^{-5}$ & -0.0737
\end{tabular}

\section{Nomenclature}




$\begin{array}{ll}k_{i j} & \begin{array}{l}\text { Binary interaction coefficients between } \\ \text { component } i \text { and component } j\end{array} \\ Z_{i}^{\text {pred }} & \begin{array}{l}\text { Predicting sulfur solubility with model } \\ \text { Sulfur solubility from experiment }\end{array} \\ Z_{i}^{\text {exp }} & \text { Binary interaction coefficient between } \mathrm{S}_{8} \\ k_{\mathrm{S}_{8}-\mathrm{H}_{2} \mathrm{~S}} & \text { and } \mathrm{H}_{2} \mathrm{~S} \\ k_{\mathrm{S}_{8}-\mathrm{CO}_{2}} & \text { Binary interaction coefficient between } \mathrm{S}_{8} \\ & \text { and } \mathrm{CO}_{2} \\ k_{\mathrm{S}_{8}-\mathrm{CH}_{4}} & \text { Binary interaction coefficient between } \mathrm{S}_{8} \\ & \text { and } \mathrm{CH}_{4}\end{array}$

\section{Subscripts and superscripts}

$\begin{array}{ll}i, j & \text { Species index } \\ \mathrm{S} & \text { Solid sulfur } \\ \mathrm{V} & \text { Vapor } \\ \mathrm{sat} & \text { Saturation } \\ \mathrm{r} & \text { Reduced state } \\ \mathrm{c} & \text { Critical state } \\ \text { pre } & \text { Predicting results } \\ \text { exp } & \text { Experimental data }\end{array}$

\section{Acknowledgements}

This study was financially supported by the National Natural Science Foundation of China (No. 51674213, 51504206, 1604233 and 51474184).

\section{References}

$1 \mathrm{~S}$. Li, F. Yang and F. Liu, A discussion on the sulphur deposition in the ground surface gathering and transmission system of the Puguang Gas Field, Nat. Gas Ind., 2011, 31, 74-79.

2 G. Zhu, S. Zhang, J. Li and Q. Jin, Formation and distribution of hydrogen sulfide bearing gas in China, Petroleum Exploration and Development, 2004, 31, 18-21.

$3 \mathrm{H}$. Kennedy and D. Wieland, Equilibrium in the Methanecarbon Dioxide-hydrogen Sulfide-sulfur System, Petrol. Trans. AIME, 1960, 219, 166-169.

4 B. Roberts, The Effect of Sulfur Deposition on Gas Well Inflow Performance, SPE Reservoir Eng., 1997, 12, 118-123.

5 J. David, Elemental Sulphur Formation in Natural Gas Transmission Pipelines, The University of Western Australia, , Perth2005.

6 J. Santos, A. Lobato, C. Moraes, A. Cunha, G. Silva and L. Santos, Comparison of different processes for preventing deposition of elemental sulfur in natural gas pipelines: A review, J. Nat. Gas Sci. Eng., 2016, 32, 364-372.

7 J. Hu, Z. Lei, Z. Chen and Z. Ma, Effect of sulphur deposition on well performance in a sour gas reservoir, Can. J. Chem. Eng., 2017, 1-9.

8 X. Guo, P. Wang, J. Liu, G. Song, H. Dang and T. Gao, Gaswell water breakthrough time prediction model for high- sulfur gas reservoirs considering sulfur deposition, J. Pet. Sci. Eng., 2017, 157, 999-1006.

9 C. Andre and J. David, $S_{8}$ threatens natural gas operations, environment, Oil Gas J., 1997, 95, 74-79.

10 X. Guo and Q. Wang, A new prediction model of elemental sulfur solubility in sour gas mixtures, J. Nat. Gas Sci. Eng., 2016, 31, 1875-5100.

$11 \mathrm{~J} . \mathrm{Hu}, \mathrm{J}$. Zhao, L. Wang and L. Meng, Prediction model of elemental sulfur solubility in sour gas mixtures, J. Nat. Gas Sci. Eng., 2014, 18, 31-38.

$12 \mathrm{~J}$. Mao, X. Yang and D. Wang, Optimization of effective sulfur solvents for sour gas reservoir, J. Nat. Gas Sci. Eng., 2016, 36, 463-471.

13 J. Roof, Solubility of Sulfur in Hydrogen Sulfide and in Carbon Disulfide at Elevated Temperature and Pressure, SPEJ, Soc. Pet. Eng. J., 1971, 11, 272-276.

14 S. Swift, F. Manning and R. Thompson, Sulfur-bearing Capacity of Hydrogen Sulfide Gas, SPEJ, Soc. Pet. Eng. J., 1976, 16, 57-64.

15 E. Brunner and W. Woll, Solubility of Sulfur in Hydrogen Sulfide and Sour Gases, SPEJ, Soc. Pet. Eng. J., 1980, 20, 377-384.

16 M. Gu, Q. Li, S. Zhou, W. Chen and T. Guo, Experimental and Modeling Studies on the Phase Behavior of High $\mathrm{H}_{2} \mathrm{~S}$ content Natural Gas Mixtures, Fluid Phase Equilib., 1993, 82, 173-182.

17 J. Serin, S. Jay, P. Cézac, F. Contamine, J. Mercadier, C. Arrabie and J. Legros-Adrian, Experimental Studies of Solubility of Elemental Sulphur in Supercritical Carbon Dioxide, J. Supercrit. Fluids, 2010, 53, 12-16.

18 E. Cloarec, J. Serin, P. Cézac, F. Contamine, J. Mercadier, A. Louvat, A. Lopez, P. Caneghem, R. Forster and U. Kim, Experimental Studies of Solubility of Elemental Sulfur in Methane at 363.15 K for Pressure Ranging From (4 to 25) MPa, J. Chem. Eng. Data, 2012, 57, 1222-1225.

19 K. Karan, R. Heidemann and L. Behie, Sulfur Solubility in Sour Gas: Predictions with an Equation of State Model, Ind. Eng. Chem. Res., 1998, 37, 1679-1684.

20 A. Eslamimanesh, A. Mohammadi and D. Richon, Thermodynamic Consistency Test for Experimental Data of Sulfur Content of Hydrogen Sulfide, Ind. Eng. Chem. Res., 2011, 50, 3555-3563.

21 A. Eslamimanesh, A. Mohammadi and D. Richon, Determination of Sulfur Content of Various Gases Using Chrastil-Type Equations, Ind. Eng. Chem. Res., 2011, 50, 7682-7687.

22 A. Mohammadi and D. Richon, Estimating Sulfur Content of Hydrogen Sulfide at Elevated Temperatures and Pressures Using an Artificial Neural Network Algorithm, Ind. Eng. Chem. Res., 2008, 47, 8499-8504.

23 M. Mehrpooya, A. Mohammadi and D. Richon, Extension of an Artificial Neural Network Algorithm for Estimating Sulfur Content of Sour Gases at Elevated Temperatures and Pressures, Ind. Eng. Chem. Res., 2009, 49, 439-442.

24 B. Zarenezhad and A. Aminian, Predicting the Sulfur Precipitation Phenomena During the Production of Sour 
Natural Gas by Using an Artificial Neural Network, Pet. Sci. Technol., 2011, 29, 401-410.

25 R. Heidemann, A. Phoenix, K. Karan and L. Behie, A Chemical Equilibrium Equation of State Model for Elemental Sulfur and Sulfur-containing Fluids, Ind. Eng. Chem. Res., 2001, 40, 2160-2167.

26 C. Sun and G. Chen, Experimental and Modeling Studies on Sulfur Solubility in Sour Gas, Fluid Phase Equilib., 2003, 214, 187-195.
27 P. Cézac, J. Serin, J. Mercadier and G. Mouton, Modelling Solubility of Solid Sulphur in Natural Gas, Chem. Eng. J., 2007, 133, 283-291.

$28 \mathrm{~J}$. Smith, H. Van ness and M. Abbott, Introduction to chemical engineering thermodynamics, The McGraw-Hill Companies, 7 th edn, 2005.

29 X. Shuai and A. Meisen, New correlations predict physical properties of elemental sulfur, Oil Gas J., 1995, 93, 50-55.

30 D. Peng and D. Robinson, A New Two-Constant Equation of State, Ind. Eng. Chem. Fundam., 1976, 15, 59-64. 